\title{
Modern High Resolution NMR for the Study of Structure, Dynamics and Interactions of Biological Macromolecules
}

\author{
By T. Stangler, R. Hartmann, D. Willbold, and B. W. Koenig* \\ Institut für Strukturbiologie, IBI-2, Forschungszentrum Jülich, D-52425 Jülich, \\ Germany \\ Institut für Physikalische Biologie, Heinrich-Heine-Universität Düsseldorf, \\ D-40225 Düsseldorf, Germany
}

(Received March 15, 2006; accepted March 17, 2006)

\section{Solution NMR / Structure / Dynamics / Interactions}

High resolution liquid state nuclear magnetic resonance spectroscopy (NMR) is a powerful technique for in vitro studies of structure and dynamics of soluble biological macromolecules under physiological conditions. The unique combination of atomically resolved structural data with both local and global dynamic features covering the entire range of time scales from picoseconds to seconds makes NMR the method of choice in a very diverse and rapidly growing array of biochemical, biomedical, and pharmaceutical applications. After briefly introducing the basic principles of liquid state NMR we review recent methodological and instrumental advances in the field of biologically focused high resolution NMR. The main emphasis of the second part is on molecular interactions. Such interactions are fundamental for the function of proteins in living systems, e.g. for signal transduction, enzymatic catalysis, and immune defense. The tremendous opportunities of high resolution NMR in the identification and detailed characterization of the sites and modes of molecular interactions will be demonstrated.

\section{Introduction}

Nuclei most frequently encountered in NMR studies of proteins are the magnetically active spin $1 / 2$ isotopes ${ }^{1} \mathrm{H},{ }^{15} \mathrm{~N}$, and ${ }^{13} \mathrm{C}$ and the spin 1 nucleus ${ }^{2} \mathrm{H}$. Resonance frequencies (in $\mathrm{MHz}$ ) are proportional to the field strength $B_{0}$

\footnotetext{
* Corresponding author. E-mail: b.koenig@fz-juelich.de
} 


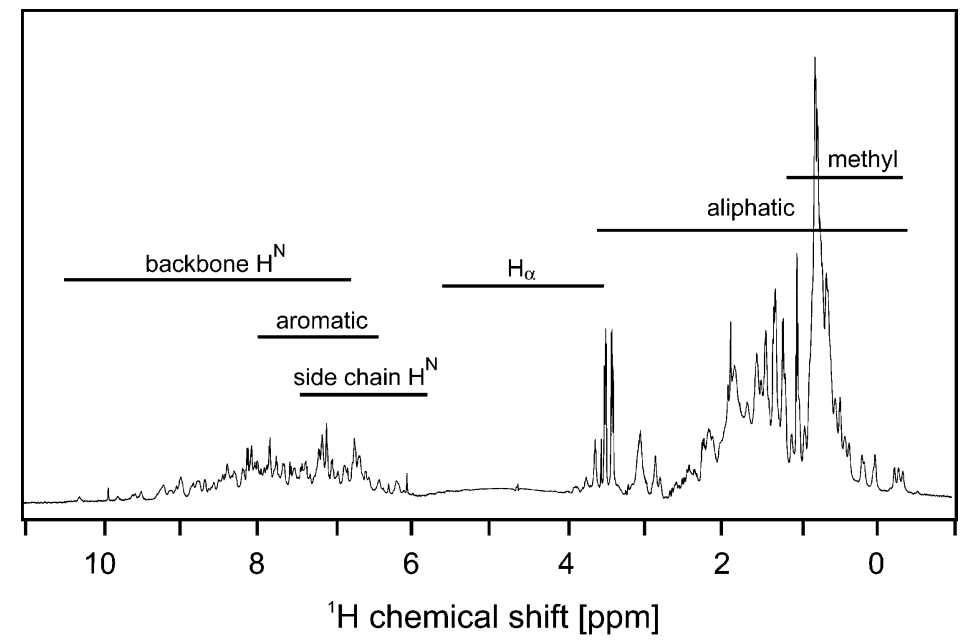

Fig. 1. High resolution ${ }^{1} \mathrm{H}$ NMR spectrum of a small protein. Typical chemical shift ranges of specific types of protein protons are indicated.

of the NMR magnet and the gyromagnetic ratio $\gamma$, an isotope-specific constant. For example, the resonance frequencies of ${ }^{1} \mathrm{H},{ }^{13} \mathrm{C}$, and ${ }^{15} \mathrm{~N}$ nuclei are 600,150 and $60 \mathrm{MHz}$, respectively, in a $B_{0}$ field of $14.1 \mathrm{~T}$. Based on the ${ }^{1} \mathrm{H}$ resonance a $14.1 \mathrm{~T}$ NMR spectrometer is often referred to as a $600 \mathrm{MHz}$ instrument. The exact position and fine structure of a NMR signal in the spectrum depends on the chemical environment of the nucleus (chemical shielding, chemical shift), electron-mediated indirect spin-spin interactions (referred to as through bond, scalar, or $J$ coupling), and direct dipole-dipole interactions (referred to as through space or dipolar couplings). However, rapid and isotropic rotational diffusion of small proteins in solution may cause complete averaging of anisotropic interactions (anisotropy of chemical shift, dipolar coupling, anisotropic component of scalar coupling). Multiplet splittings due to scalar coupling may be collapsed by appropriate radiofrequency (RF) irradiation schemes. As a result, narrow resonance lines are observed that are typical for liquid state NMR spectra. A one-dimensional (1D) ${ }^{1} \mathrm{H}$ NMR spectrum of a small protein is shown in Fig. 1. Differential shielding of the external $B_{0}$ field by the electronic environment of the individual protons causes frequency dispersion. Protons with comparable chemical environment cluster. Regions occupied by certain types of ${ }^{1} \mathrm{H}$ resonances are indicated in Fig. 1. The frequency axis in Fig. 1 shows the chemical shift in parts per million (ppm) which is the ${ }^{1} \mathrm{H}$ frequency offset of the signal relative to the ${ }^{1} \mathrm{H}$ frequency of a reference compound divided by the reference frequency. The chemical shift scale is independent of the $B_{0}$ field strength of the spectrometer. 


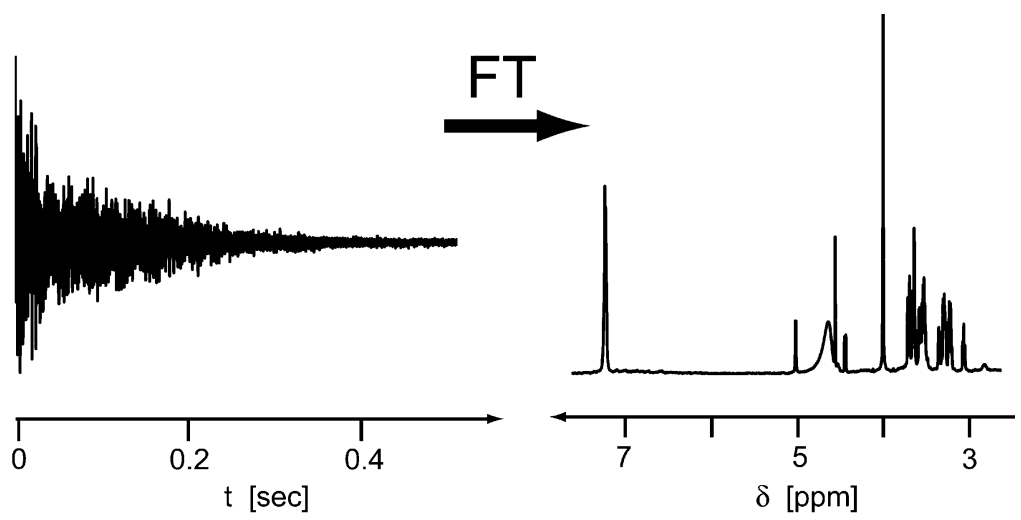

Fig. 2. Pulsed Fourier transform NMR. Transverse magnetization precessing in the receiver coil during data acquisition generates oscillating voltage. The recorded time domain signal shown on the left is referred to as free induction decay (FID). The amplitude of the FID decays in time due to relaxation. The frequency domain one-dimensional NMR spectrum on the right is obtained from the FID by a Fourier transformation. The frequency axis is typically given in ppm (see text).

Although spin-spin interactions may not always be apparent in the NMR spectrum, they are operational in the spin system and form the physical basis for many aspects of the NMR experiment. For example, Brownian motion of the protein causes rapid fluctuations of spin interactions that give rise to relaxation of the spin system from an excited to the ground state, spinspin interactions can be used for directed polarization transfer between spins, dipole-dipole interactions may cause cross-relaxation between excited spins, a phenomenon related to the nuclear Overhauser effect (NOE). A large variety of NMR experiments is available that allow to measure resonance frequencies, spin-spin interactions, relaxation rates and other NMR-related parameters that can then be interpreted in terms of protein structure, dynamics, and molecular interactions.

The evolution of solution NMR to one of the prime methods in structural biology is intimately linked to a series of outstanding methodological and technological advances that occurred over the past four decades and was reviewed in numerous papers and monographs, see for example [1-4]. The revolutionary development of Fourier transform (FT) NMR enabled the generation of an entire frequency domain spectrum from a single time domain signal, the free induction decay (FID) acquired within seconds [5] (see Fig. 2). However, interpretation of a 1D protein spectrum is very challenging due to strong signal overlap (Fig. 1). The subsequent introduction of a second frequency dimension [6] led to the development of a large number of two-dimensional (2D) NMR experiments greatly expanding the 
utility of FT NMR to complex molecules [7-9]. Around 1990 development of heteronuclear multidimensional NMR experiments in combination with heterologous expression of uniformly ${ }^{15} \mathrm{~N}$ and ${ }^{13} \mathrm{C}$ isotope-labeled proteins set the stage for high resolution structure determination and investigation of dynamic properties of larger proteins and complexes with overall size up to $\sim 25 \mathrm{kDa}$ [10-12]. We will refer to this methodology of the early 1990s and to homonuclear 2D experiments as conventional liquid state NMR, which will be introduced in Sect. 2. The process of protein structure determination by solution NMR spanning from heterologous expression of the protein to the validated structure will be described in some detail. An overview will be given on dynamic features that can be studied by NMR.

Molecular tumbling from Brownian motion slows down as the size of the biomolecule increases. Reduced motion is accompanied by faster transverse relaxation, especially for ${ }^{13} \mathrm{C}$ spins, line broadening, compromised spectral resolution and sensitivity. Rapid relaxation of transverse magnetization is responsible for the molecular weight limit of conventional liquid state NMR. However, over the past few years this size limit has been overcome by suppression of major relaxation pathways by means of protein deuteration [13] and by introduction of optimized pulse sequences based on relaxation interference [14] as discussed in Sect. 3.

Dipolar couplings depend on length and orientation of internuclear vectors and provide a rich source of structure information. However, fast isotropic tumbling of proteins in solution usually causes complete averaging of dipolar couplings in conventional liquid state spectra and prevented utilization of the geometric information in the past. Imparting a minute degree of anisotropy to the reorientational motion of the protein reintroduces small residual dipolar couplings (RDCs) into high resolution spectra without causing undue spectral complexity [15]. RDCs are highly valuable global restraints of protein structure. Development of experimental concepts for convenient measurement of RDCs has sparked widespread use of RDCs in the structure determination process of proteins and molecular complexes. Experimental aspects and applications of RDCs will be reviewed in Sect. 4.

Solution NMR is a versatile tool for analysis of molecular interactions as demonstrated in Sect. 5. As an alternative to a complete de novo structure determination of a molecular complex NMR may provide a sparse set of intermolecular or global structure restraints that are highly useful for docking of previously determined component structures. NMR techniques have been developed that allow mapping of contact sites, estimates of the interaction strength, and screening of compound libraries for potential binders of a given target molecule. NMR analysis is not restricted to strong interactions but is sensitive to weak binding down to the millimolar range, too. 


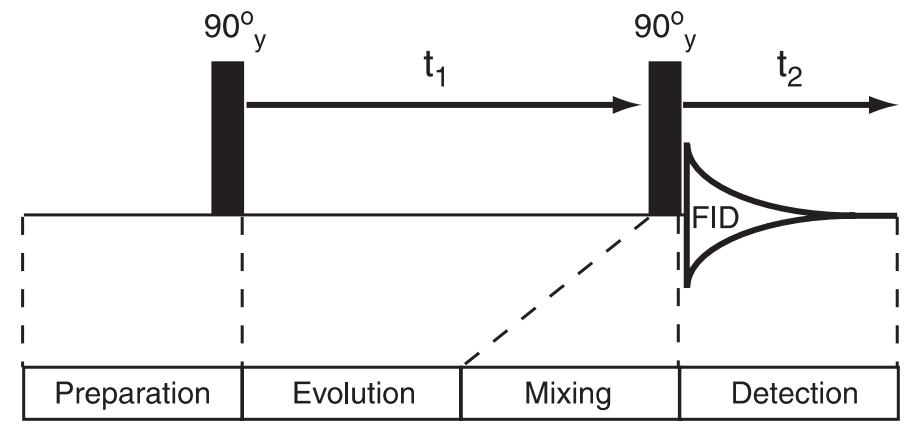

2D

\begin{tabular}{|l|l|l|l|}
\multicolumn{2}{c}{$\mathrm{t}_{1}$} & \multicolumn{1}{c}{$\mathrm{t}_{2}$} \\
\hline $\mathrm{P}$ & $\mathrm{E}_{1}$ & $\mathrm{M}_{1}$ & $\mathrm{D}$ \\
\hline
\end{tabular}

$3 \mathrm{D}$

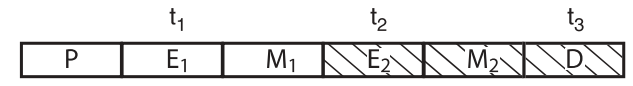

4D

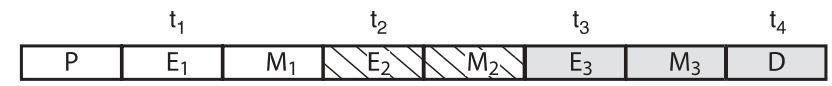

Fig. 3. Schematic representation of multidimensional NMR experiments. The pulse sequence of a 2D COSY experiment is shown in the upper part. In a conventional COSY experiment both the preparation and the mixing periods consist of single $90^{\circ} \mathrm{RF}$ pulses. The indirect time domain (incremented delay, $t_{1}$ ) and the direct time domain (time passing during acquisition of the FID, $t_{2}$ ) are sampled during evolution and detection periods, respectively. A formal extension of the basic scheme from two- (2D) to three- (3D) and four-dimensional (4D) NMR experiments is shown below.

\section{Protein structure and dynamics by conventional liquid NMR}

\subsection{Homonuclear 2D NMR}

Formally a 2D NMR experiment can be subdivided into four segments: A preparation period which establishes a desired non-equilibrium state of the spin system, an evolution period containing an incremented time delay $\left(t_{1}\right)$ which labels the spins by their chemical shift, a mixing period during which the spins are correlated with each other, and a detection period during which a digitized FID is recorded in the direct time domain $\left(t_{2}\right)$ (see Fig. 3). In all four periods the spin system can be subject to well-defined, experiment-specific perturbations (RF or field gradient pulses) and delays. A 2D data set consists of a series of $n$ FIDs recorded with identical pulse scheme except for the vari- 
able delay $t_{1}$. Fourier transformation in $t_{2}$ provides a series of $n$ 1D spectra with sinusoidal intensity modulations along $t_{1}$. A second FT along $t_{1}$ yields the desired 2D spectrum in frequency space. The correlations between resonance frequencies $\left(\omega_{1}, \omega_{2}\right)$ observed in a 2D NMR spectrum are determined by polarization transfer between interacting spins occurring during the mixing period. Polarization transfer may be mediated by scalar coupling (through bonds) or by dipolar couplings (through space). 2D experiments based on $J$-correlated magnetization transfer can be used to identify resonances of spins connected by a limited number of two or three intervening bonds (e.g. correlated spectroscopy (COSY) [7]) or to map out networks of covalently connected spins (e.g. total correlation spectroscopy (TOCSY) [16]). The nuclear Overhauser effect (NOE) involves polarization transfer through dipolar couplings and is used to identify spins that are close in space but perhaps belong to residues far apart in the protein sequence. For sufficiently short mixing times the NOE shows an $r^{-6}$ dependence which can be used to quantify interproton distances up to $\sim 0.5 \mathrm{~nm}$ by the nuclear Overhauser enhancement spectroscopy (NOESY) experiment [17]. Another important class of structural restraints are threebond homonuclear $J$ couplings that are related to backbone torsion angles by a Karplus-type relationship [18].

Prime advantages of $2 \mathrm{D}^{1} \mathrm{H}-{ }^{1} \mathrm{H}$ NMR spectra over $1 \mathrm{D}$ NMR experiments in studies of small proteins are improved resonance dispersion and a much higher information content based on the large number of correlations found in a single 2D spectrum. Strategies were developed to assign the observed resonances to individual protons of the biopolymer. A combination of ${ }^{1} \mathrm{H}-{ }^{1} \mathrm{H} J$ correlationand NOE-type experiments can be used to establish intraresidue and sequential connectivities, respectively [1]. First low resolution structures of small proteins determined with homonuclear 2D proton NMR were published in 1985 [19-21]. Although methodological advances greatly improved structure resolution over the next few years the homonuclear 2D NMR strategy reached its limits at a protein size around 100 residues [22,23]. Both the number of protons and the rotational correlation time increase with protein size, resulting in spectral crowding and resonance line broadening that cannot be resolved in two dimensions. 2D homonuclear methodology begins to fail once the ${ }^{1} \mathrm{H}$ line width exceeds the relatively small ${ }^{1} \mathrm{H}^{-1} \mathrm{H}$ scalar couplings. This strongly reduces efficiency of magnetization transfer through three-bond ${ }^{1} \mathrm{H}-{ }^{1} \mathrm{H}$ scalar couplings and also blocks access to structural information encoded in the couplings [24].

\subsection{Heteronuclear 3D and 4D NMR}

In the early 1990s the new concept of multidimensional NMR matured that exploits heteronuclear $J$ couplings for magnetization transfer in highly ${ }^{15} \mathrm{~N}$ and/or ${ }^{13} \mathrm{C}$ isotope-labeled proteins. Two-dimensional heteronuclear experiments like heteronuclear single quantum coherence (HSQC) [25] or heteronu- 


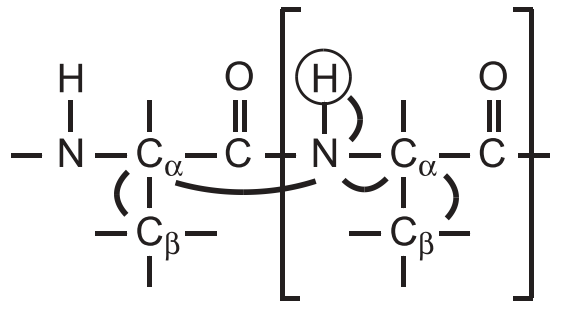

Fig. 4. Magnetization transfer in a 3D HNCACB experiment [31]. A fragment of two successive amino acid residues is sketched. Polarization of the amide proton (circled) of a given residue (bracketed) is relayed to the directly bound ${ }^{15} \mathrm{~N}$ spin and then to the ${ }^{13} \mathrm{C}_{\alpha}$ and ${ }^{13} \mathrm{C}_{\beta}$ spins of the same and of the preceding amino acid via one- and two-bond $J$ couplings. Magnetization is transferred back to $\mathrm{H}^{\mathrm{N}}$ for detection.

clear multiple quantum coherence (HMQC) schemes [26] had been introduced already in the 1980s. Relatively large one-bond $J$ couplings between ${ }^{13} \mathrm{C}$ and ${ }^{15} \mathrm{~N}$ spins and between protons and their directly attached ${ }^{15} \mathrm{~N}$ or ${ }^{13} \mathrm{C}$ nuclei allow efficient polarization transfer for larger proteins well in excess of 100 residues. Increasing the dimensionality of the NMR experiment to $3 \mathrm{D}$ or $4 \mathrm{D}$ strongly alleviates the problem of resonance overlap [27,28]. Formally a 3D pulse scheme is a concatenation of two $2 \mathrm{D}$ experiments where the first $2 \mathrm{D}$ experiment lacks a detection period and replaces the preparation period of the second 2D experiment (see Fig. 3). Repetition of this strategy leads to 4D experiments. As a result, a 3D (4D) experiment contains two (three) pairs of mutually independent mixing and time-incremented evolution periods. Simple examples of 3D experiments are heteronuclear edited ${ }^{1} \mathrm{H}^{1} \mathrm{H}$ spectra (e.g. 3D ${ }^{1} \mathrm{H},{ }^{15} \mathrm{~N}-\mathrm{HSQC}-\mathrm{NOESY}$ [28]). In the homonuclear 2D version magnetization is transferred from an originating proton to a destination proton and correlation peaks in the $2 \mathrm{D}$ plane reflect the chemical shifts of the interacting protons. In the 3D spectrum the peaks are displaced along an additional axis. For example, the third dimension can be the chemical shift of the ${ }^{15} \mathrm{~N}$ or ${ }^{13} \mathrm{C}$ spins directly bound to the originating or destination protons, respectively. Ambiguities may still exist in a 3D ${ }^{15} \mathrm{~N}$ - or ${ }^{13} \mathrm{C}$-edited NOESY. Usually they can be resolved in a 4D experiment where the ${ }^{1} \mathrm{H}-{ }^{1} \mathrm{H}$ cross-peaks are dispersed by the chemical shifts of both heteronuclei directly bound to the originating and the destination protons, respectively [29].

The combination of ${ }^{1} \mathrm{H}$ detection with multi-step magnetization transfer via well-resolved heteronuclear $J$ couplings in triple resonance 3D or 4D NMR experiments provides both high sensitivity and resolution [30]. Couplings that belong to the same class have rather uniform size throughout the protein (e.g. $90-100 \mathrm{~Hz}$ for amide ${ }^{1} \mathrm{H}^{\mathrm{N}}{ }^{15} \mathrm{~N}$ or $\sim 140 \mathrm{~Hz}$ for ${ }^{1} \mathrm{H}_{\alpha^{-}}{ }^{13} \mathrm{C}_{\alpha}$, see [10] for a comprehensive list) and are largely independent of protein conformation, which allows construction of pulse schemes that simultaneously excite a particular pathway for all amino acids in the protein and result in the observation of well- 


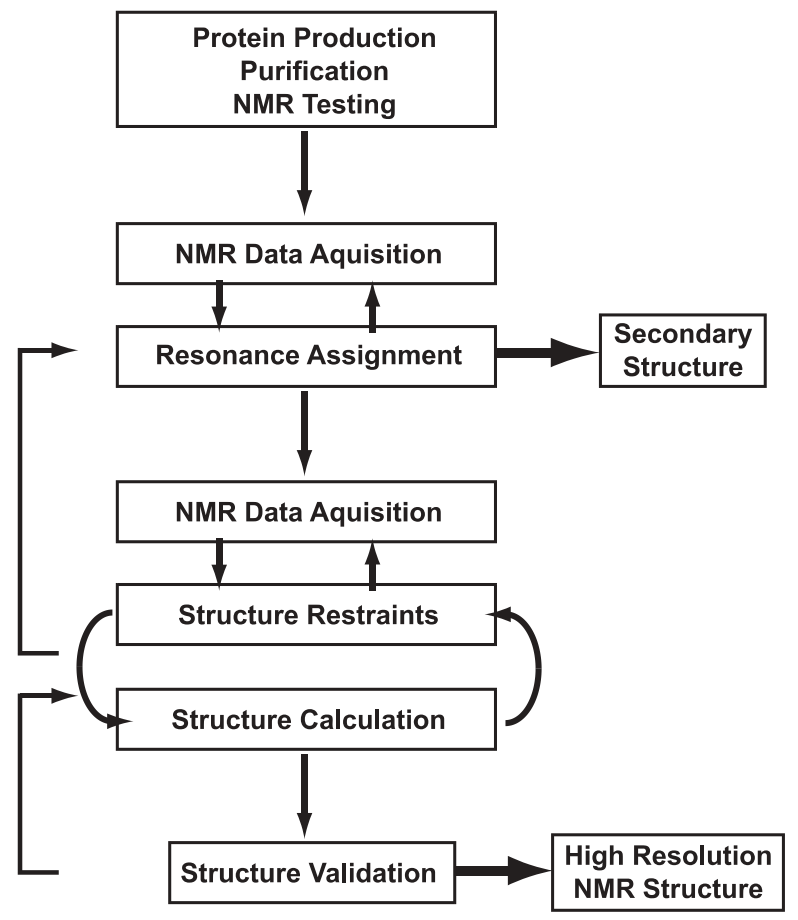

Fig. 5. Flowchart summarizing the basic steps of protein structure determination by solution NMR.

defined types of correlations, e.g. the 3D HNCO experiment correlates the $\mathrm{H}^{\mathrm{N}}$ and ${ }^{15} \mathrm{~N}$ chemical shifts of an amino acid with the carbonyl ${ }^{13} \mathrm{C}$ chemical shift of the preceding residue [30]. The polarization transfer pathway employed in $J$-correlated pulse schemes for resonance assignment is usually apparent from the name of the experiment. For example, in a 3D HNCACB scheme $\mathrm{H}^{\mathrm{N}}$ magnetization is relayed via the directly attached ${ }^{15} \mathrm{~N}$ spin to ${ }^{13} \mathrm{C}_{\alpha}$ and ${ }^{13} \mathrm{C}_{\beta}$ of both the same and the preceding amino acid, respectively (Fig. 4) [31].

\subsection{Protein structure determination}

The NMR experiments discussed above are embedded in the process of NMR structure determination of soluble proteins or molecular complexes. The main steps of this process are arranged in a flow chart in Fig. 5.

\subsubsection{Recombinant protein production and purification}

Large amounts (milligrams) of purified, functionally folded, and isotopelabeled protein are required for NMR structure determination. Most frequently 
the bacterial host Escherichia coli is used for heterologous production of isotope-labeled target protein [32,33]. A large number of bacterial expression vectors and host cell lines are commercially available. DNA that codes for the target protein is inserted into appropriate vectors using established cloning techniques [34]. A range of expression cell lines is screened for optimal protein production [35]. Uniform ${ }^{15} \mathrm{~N}$ and/or ${ }^{13} \mathrm{C}$ isotope labeling of the protein is critically important for the heteronuclear NMR experiments described here. The labeling is easily accomplished if the protein can be expressed in high yield in bacteria that are grown in minimal medium supplemented by ${ }^{15} \mathrm{NH}_{4} \mathrm{Cl}$ and/or ${ }^{13} \mathrm{C}_{6}$-glucose as the sole nitrogen and carbon sources, respectively.

Other organisms are available for expression of isotope-labeled protein if production in bacterial cells fails or in case of eukaryotic proteins that require posttranslational modifications. These systems include the yeast Pichia pastoris [36, 37], baculovirus-infected SF9 insect cells [38,39], or mammalian CHO cells [40]. In particular the $P$. pastoris system allows straightforward genetic manipulations, provides high yield of labeled target protein, and is capable of various posttranslational modifications required for higher eukaryotic proteins [41]. Finally, cell-free expression has been established as an alternative route for high yield synthesis of proteins that are toxic to cellular hosts or prone to aggregation [42] and is very promising for biochemical production of transmembrane proteins [43]. The in vitro batch system contains all components of the cellular machinery that are required for transcription and translation, in particular all enzymes involved in protein expression. Bacterial extracts are a convenient source of these macromolecular components. The batch system is continuously supplemented with nutrients and substrates, which allows for uniform or amino acid-specific isotope labeling.

Following expression, an efficient protocol for protein purification and perhaps refolding must be established. Biological activity of the biochemically produced protein should be verified using appropriate assays. Optimization of the protein production process might take anywhere from weeks to months.

There are substantial efforts to speed up protein production by use of robotic platforms for automated cloning, expression, and purification of proteins [44].

\subsubsection{NMR testing}

Initial NMR experiments check suitability of the expressed target protein for NMR structure determination. Ideally, the protein should form a stable monomer that tumbles rapidly in solution. The rotational correlation time is sensitive to volume and shape of the solute and can be estimated from measured relaxation times [45]. Presence of heterogeneous multimers or protein aggregation is detrimental to NMR structure determination. Exclusive formation of a single homomultimeric species or of a unique heteromultimer in more complex systems may be acceptable as long as the size of the aggregate 
does not exceed the size limit of the NMR methodology used $(\sim 25 \mathrm{kDa}$ for conventional 3D NMR on non-deuterated protein). Buffer and environmental conditions must be established under which the protein sample remains stable at a minimum of several days that are required to record a single 3D NMR experiment. A wide dispersion of the amide proton chemical shifts and the occurrence of methyl proton signals at negative ppm values in a $1 \mathrm{D}$ proton spectrum indicate a folded protein ( $c f$. Fig. 1). The number ratio of observed-toexpected backbone amide ${ }^{1} \mathrm{H}-{ }^{15} \mathrm{~N}$ correlation peaks in a 2D HSQC experiment (Fig. 6) gives a first hint on the expected sensitivity of heteronuclear 3D experiments under the conditions chosen. If it turns out to be impossible to find conditions favorable for NMR structure determination, then one might want to rationally reengineer the target protein, e.g. by substituting amino acids or deleting sequence stretches that are suspected to play a role in unwanted aggregation. Care must be taken in avoiding structural changes of the target protein and in ensuring the mutant protein is functional.

\subsubsection{NMR data collection}

Acquisition of heteronuclear triple resonance 3D data sets for resonance assignment is started once a well-behaved, uniformly ${ }^{15} \mathrm{~N} /{ }^{13} \mathrm{C}$-labeled protein is at hand (Fig. 5). A large variety of such 3D experiments has been developed that correlate well-defined sets of nuclei within a given amino acid (intraresidue connectivity) and/or in consecutive residues (sequential connectivity) (reviewed in [46], see Fig. 4). Efficient use of 3D heteronuclear NMR data for ${ }^{1} \mathrm{H}$ resonance assignment necessitates resonance assignment of the ${ }^{15} \mathrm{~N}$ and ${ }^{13} \mathrm{C}$ spins, too. A small subset of strategically chosen $J$-correlated triple resonance $3 \mathrm{D}$ experiments is often sufficient for close to complete backbone resonance assignment. The choice of experiments depends on size and rotational correlation time of the protein studied, degree of resonance overlap, and isotope labeling scheme employed. The set of standard 3D experiments preferred in our laboratory for sequential backbone assignment of medium sized proteins (up to $\sim 20 \mathrm{kDa}$ ) includes the already mentioned HNCACB and HNCO schemes and the HNHA (intraresidue correlation of amide $\mathrm{H}^{\mathrm{N}}$ and ${ }^{15} \mathrm{~N}$ with $\mathrm{H}_{\alpha}$ ) [47]. Initial experiments for assignment of aliphatic side chain carbons and protons are $\mathrm{C}(\mathrm{CO}) \mathrm{NH}$ (correlates side chain ${ }^{13} \mathrm{C}$ with amide $\mathrm{H}^{\mathrm{N}}$ and ${ }^{15} \mathrm{~N}$ of the next residue) [48] and $\mathrm{HCCH}-\mathrm{COSY}$ (correlates adjacent ${ }^{13} \mathrm{C}$ resonances in an aliphatic side chain, provides chemical shifts of ${ }^{13} \mathrm{C}$ and directly bound ${ }^{1} \mathrm{H}$ ) [49]. The tedious assignment of side chain protons is an important prerequisite for determination of high resolution NMR structures. ${ }^{13} \mathrm{C}_{\alpha}$ and ${ }^{13} \mathrm{C}_{\beta}$ chemical shifts are particularly valuable since they provide a link between experiments aimed at backbone and side chain assignment, respectively, and they are indicative of the type of amino acid [50] and the local secondary structure [51]. Depending on the sensitivity of a particular experiment, the size of the protein, and the available spectrometer hardware it takes between several 
hours and a few days to record a single 3D NMR spectrum using a sample of $\sim 300 \mu \mathrm{l}$ at 1 to $2 \mathrm{mM}$ protein concentration. Recording a basic set of 3D experiments for resonance assignment requires about one to three weeks instrument time on a high field NMR spectrometer.

\subsubsection{Resonance assignment}

The assignment process is very time consuming. Even for a medium size protein more than thousand resonance frequencies need to be matched with the corresponding nuclei. Sophisticated software is available for processing (e.g. NMR Pipe [52]) and computer-aided analysis of multidimensional NMR data sets (e.g. PIPP [53], XEASY [54], NMR View [55], CARA [56]). These programs assist the user in the various steps of the manual assignment process like peak picking, book keeping, mutual alignment of resonances/stripes observed in separate 3D experiments. The highly systematic nature of heteronuclear $J$-correlated 3D experiments together with the limited number and specific NMR signatures of naturally occurring amino acid types triggered development of software for semiautomatic and fully automated resonance assignment of medium sized proteins ( $c a$. 50 to 150 residues) [57-60]. Current efforts are directed towards extending automatic backbone assignment to significantly larger proteins [61]. The correlation of the chemical shift of $\mathrm{H}_{\alpha}$ protons and ${ }^{13} \mathrm{C}_{\alpha}$ and ${ }^{13} \mathrm{C}_{\beta}$ carbons with secondary structure allows a preliminary assessment of the protein secondary structure at this stage [51,62]. An annotated $2 \mathrm{D}{ }^{1} \mathrm{H},{ }^{15} \mathrm{~N}$-HSQC spectrum of the ${ }^{15} \mathrm{~N}$ isotope-labeled human $\mathrm{GABA}_{\mathrm{A}}$ receptor-associated protein (GABARAP) [63] is shown in Fig. 6.

\subsubsection{NMR-based structure restraints}

A second set of 3D and perhaps 4D experiments is recorded with the aim to derive NMR-based structure restraints (Fig. 5). Thousands of approximate ${ }^{1} \mathrm{H}-{ }^{1} \mathrm{H}$ distances can be obtained from the cross-peak intensities in heteronuclear edited NOESY spectra and provide traditionally the main source of structural information. Backbone and side chain torsion angles are related to three-bond scalar couplings [64]. Most frequently, the dihedral backbone angle $\varphi$ is restrained by the $\mathrm{H}^{\mathrm{N}}-\mathrm{H}_{\alpha}$ coupling or by heteronuclear couplings [65] while side chain torsion angles are related to the $\mathrm{H}_{\alpha}-\mathrm{H}_{\beta}$ coupling and to various heteronuclear couplings [12]. Such small couplings are difficult to be measured directly but may be obtained from E.COSY-based schemes [66] or from quantitative $J$ correlation experiments [67]. The dihedral backbone angle $\psi$ is related to cross-correlated relaxation rates that can be measured with heteronuclear $3 \mathrm{D}$ NMR $[68,69]$. A coarse classification of the backbone dihedral angles $\varphi$ and $\psi$ can also be based on comparison of intensities of intraresidue and sequential $(i, i+1) \mathrm{H}_{\alpha}-\mathrm{H}^{\mathrm{N}}$ NOESY cross-peaks [1].

Another source of structure information is chemical shift. The computer program TALOS predicts backbone torsion angles of the central residue in 


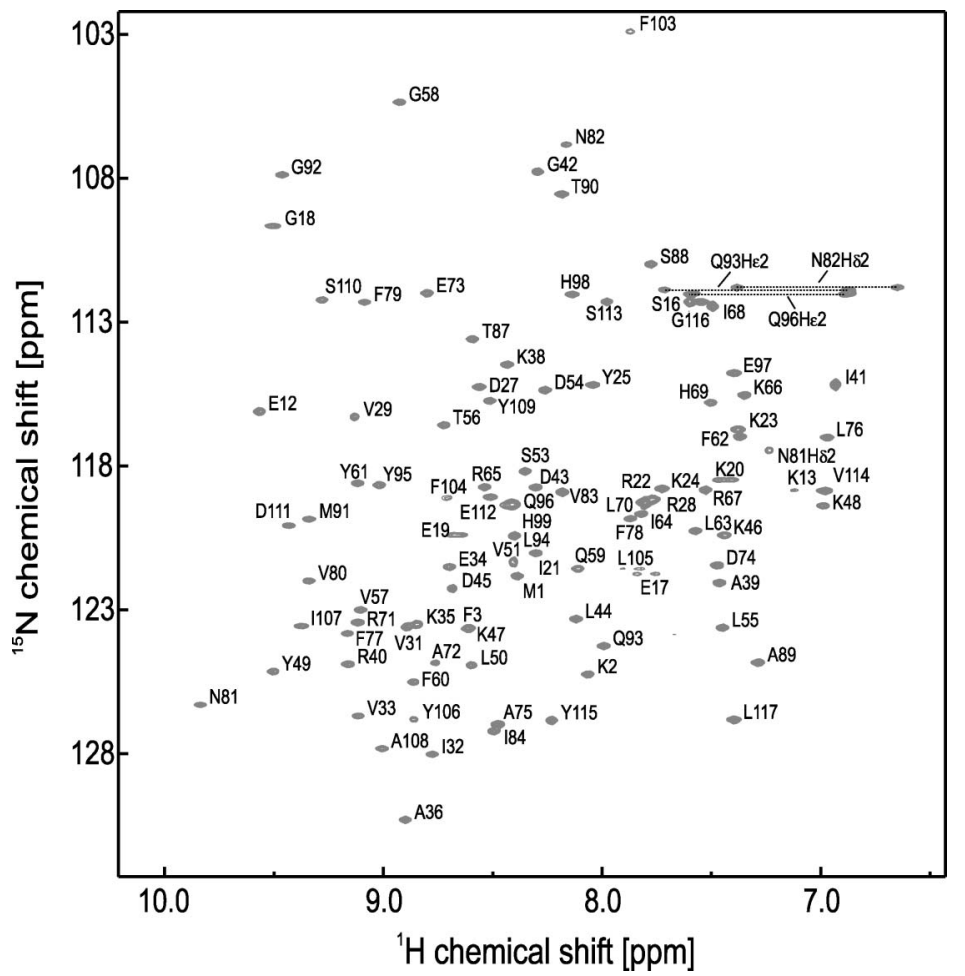

Fig. 6. Two-dimensional ${ }^{1} \mathrm{H},{ }^{15} \mathrm{~N}-\mathrm{HSQC}$ spectrum of ${ }^{15} \mathrm{~N}$ isotope-labeled human $\mathrm{GABA}_{\mathrm{A}}$ receptor-associated protein (GABARAP) [63]. The ${ }^{1} \mathrm{H}^{15}{ }^{15} \mathrm{~N}$ correlations visible in the spectrum specify ${ }^{1} \mathrm{H}$ and ${ }^{15} \mathrm{~N}$ chemical shifts of directly bound pairs of nuclei in the protein backbone (labeled with the one-letter-amino-acid-code and the residue number) and side chains (side chain protons specified).

a triplet of adjacent residues. This is done by matching measured sets of ${ }^{13} \mathrm{C}_{\alpha},{ }^{13} \mathrm{C}_{\beta},{ }^{13} \mathrm{C}^{\prime},{ }^{1} \mathrm{H}_{\alpha},{ }^{15} \mathrm{~N}$ chemical shifts of all three residues with databasedeposited shift values of sequence-related triplets of consecutive residues in proteins for which highly resolved X-ray structures are available [70]. Chemical shifts of non-exchangeable protons are reliably predicted form high resolution protein structures [71]. Comparison of experimental chemical shifts with those predicted for a trial structure is highly useful in the process of structure determination [72].

The existence and strength of hydrogen bonds is reflected by electronmediated scalar couplings which allows an unambiguous link between hydrogen bond donor and acceptor atoms by NMR [73-75].

The restraints mentioned above are purely local and solely define the shortrange order of atoms that are close in space. This might pose a serious problem, 
e.g. for elongated structures or multidomain proteins if only a limited number of interdomain NOEs could be derived. Fortunately, over the last 10 years a number of NMR-derived restraints became available that define both shortand long-range order. Several methods rely on slightly anisotropic rotational diffusion of the protein studied and relate the orientation of internuclear vectors to a common reference frame. Orientational restraints have been obtained from residual dipolar couplings (RDCs) $[15,76]$, heteronuclear $T_{1} / T_{2}$ relaxation time ratios [77], and chemical shielding anisotropy measurements [78, 79]. In paramagnetic metalloproteins or proteins that bear a paramagnetic spin label pseudocontact shifts are linked to orientational and long-range distance information while paramagnetic relaxation effects provide long-range distance restraints [80-82].

\subsubsection{Structure calculation and validation}

The ultimate stage of the NMR structure determination process is a computerbased search for protein conformations that are in agreement with the entire set of NMR-derived structure restraints. For this purpose a potential energy function, $E_{\text {tot }}$, is build that sums up terms reflecting the generally valid covalent geometry of proteins (bonds lengths, angles, planarity, and chirality) and non-bonded contacts in addition to the NMR-derived structure restraints [83]. Deviations of a trial structure from covalent geometry or NMR-derived restraints can be expressed by square or quasi-harmonic potentials while a range of different energy functions is used for evaluation of non-bonded contacts. Search algorithms have been devised for unbiased and efficient sampling of conformational space with the objective to localize the global minimum of the very complex target function $E_{\text {tot }}$ which has multiple local minima. Simulated annealing (SA) with restrained molecular dynamics (MD) for structure generation is used in many laboratories for this search and has been implemented in software packages like Dyana [84], CNS [85] and XPLOR-NIH [86]. During SA the trial protein structure is initially "heated up" by means of a kinetic energy term to facilitate crossing of energy barriers and to prevent the structure from getting trapped in a local minimum followed by slow cooling to yield an energy-minimized stable conformation [87]. Efficiency of sampling conformational space by SA improves significantly if the MD simulation is conducted in torsion angle space (often referred to as internal coordinates) rather than Cartesian space [88]. The large and rapidly growing number of high resolution structures in databases led to the construction of so called "database potentials" that are derived from statistical analysis of high quality structures and can supplement conventional restraints in MD-driven SA. For example, database potentials of mean force were used to improve the description of non-bonded contacts $[89,90]$.

The SA protocol is run repeatedly to obtain a representative set of structures that satisfy the experimental restraints. An ensemble of 15 calculated 

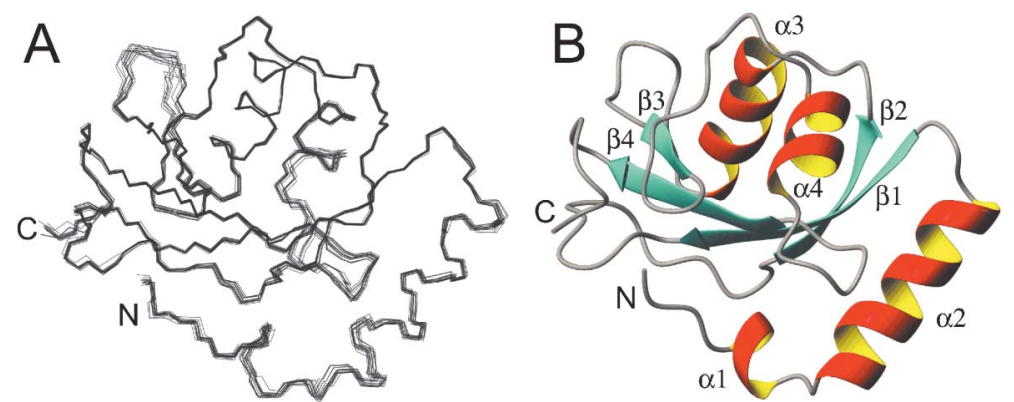

Fig. 7. Solution structure of GABARAP [91]. The $14 \mathrm{kDa}$ protein is involved in trafficking and targeting of type A receptors of the neurotransmitter GABA to inhibitory synapses [92, 93]. GABARAP exhibits an ubiquitin-like fold $(\beta 1, \beta 2, \alpha 3, \beta 3, \alpha 4, \beta 4)$ plus two additional $\mathrm{N}$-terminal $\alpha$-helices $(\alpha 1, \alpha 2)$ and is indeed involved in an ubiquitin-like target conjugation mechanism [94]. The NMR structure is based on NOE-derived distance restraints and was determined by simulated annealing using the program CNS. A: Superposition of the backbones of 15 calculated structures. B: Ribbon diagram of the averaged structure.

low energy NMR structures of the human $\mathrm{GABA}_{\mathrm{A}}$ receptor-associated protein (GABARAP) is shown in Fig. 7 together with the averaged structure [91].

The precision of the calculated conformations is directly related to the number and quality of experimental restraints used for structure generation and is reflected by the mutual root mean square deviation (RMSD) of the coordinates of selected sets of atoms in the ensemble of calculated structures. Determination of a protein structure with highest precision (backbone RMSD about $0.03-0.05 \mathrm{~nm}$ ) requires between 20 and 25 restraints per residue and depends critically on stereospecific assignment of prochiral groups [95]. Locally increased RMSD values indicate less defined local structure elements, often found in loops and at the termini of proteins. Whether this is due to either a lack of experimental constraints or increased local dynamics can be determined by experiments described in the following section.

High precision of an ensemble of calculated structures does not necessarily guarantee that the structure is accurate. Structure validation is very important and should include checks on the stereochemical quality and a survey of potential violations of NMR-derived restraints [96, 97].

The complex task of structure determination is a highly iterative process: Structures calculated in the initial rounds will very likely show restraint violations and flawed stereochemistry. Careful analysis of these problems may help to identify wrong resonance assignments and to reevaluate the NMRderived restraints. Computer programs like ARIA [98] or CYANA [99] are very promising implementations of automated NOE-based protocols for NMR structure determination. They perform multiple iterations of the following tasks: NOESY peak assignment, structure calculation, evaluation and improve- 
ment of the list of NOESY peaks [100]. These automated approaches are expected to speed up the structure determination process significantly.

\subsection{Protein dynamics}

In addition to atomically resolved protein structures NMR can provide detailed insight into dynamic processes occurring over a broad range of time scales from picoseconds to seconds with high spatial resolution [101-105]. A variety of different NMR phenomena serve as reporter or "molecular spy" of motion, e.g. spin relaxation, line shape, residual dipolar couplings, or amide proton exchange.

Spin relaxation arises from modulations of spin interactions caused by stochastic motion of the spin bearing molecule or molecular fragment. The maximum variation of the spin Hamiltonian that can result from such stochastic motion determines the time scale that is accessible by a relaxation measurement [105]. Spin relaxation processes dominated by magnetic dipole-dipole, chemical shift anisotropy (CSA), or electric quadrupolar interactions are sensitive to motions on the picosecond to nanosecond (ps-ns) time scale. Such motions include the overall rotational diffusion of soluble biomolecules and structural fluctuations in the backbone and side chains of proteins. The amide ${ }^{15} \mathrm{~N}$ and carbonyl ${ }^{13} \mathrm{C}$ spins are convenient probes of backbone dynamics while ${ }^{2} \mathrm{H},{ }^{13} \mathrm{C}$, and ${ }^{15} \mathrm{~N}$ spins are used to characterize side chain motions. Methods for measurement of laboratory frame relaxation rates $R_{1}$ and $R_{2}$ and for determination of cross-relaxation rates from heteronuclear NOEs have been reviewed [106]. The frequency spectrum of a stochastic process can be described by a spectral density function, $J(\omega)$. A procedure called spectral density mapping aims at sampling $J(\omega)$ based on a series of relaxation measurements, ideally at multiple static magnetic field strength $[107,108]$. Functional forms for $J(\omega)$ have been proposed based either on specific physical models of motion [109], on model-free formalisms that contain a limited number of free parameters [110-112], or on parameterized numerical computations [113]. Most frequently the model-free formalism is used. Fitting the experimental spectral density function to an appropriate form $J(\omega)$ provides parameters that characterize the stochastic motion of the probe. The most informative such parameter is the generalized order parameter, $S^{2}$, which characterizes the angular fluctuations of a monitored bond vector in a reference frame [110] and reflects the conformational flexibility at this specific site.

The isotropic chemical shift of a nuclear spin depends on its magnetic environment. Dynamic processes occurring on a microsecond to millisecond ( $\mu$ s-ms) time scale and involving states with pronouncedly different chemical shifts of the monitored spin are termed chemical exchange. Examples are conformational changes of a polypeptide chain or transient binding interactions. Chemical exchange is reflected in NMR line shape and transverse 
relaxation rates of affected spins. Site-specific investigation of chemical exchange with multidimensional heteronuclear NMR is preferably based on relaxation measurements. Chemical exchange processes in the protein backbone are most frequently monitored with ${ }^{15} \mathrm{~N}$ spins while ${ }^{13} \mathrm{C}$ and ${ }^{2} \mathrm{H}$ spins are used to probe side chains. In practice, transverse relaxation is measured as a function of the strength of an applied radiofrequency field using spin-lock $\left(R_{1 \rho}\right)$ or CPMG $\left(R_{2}\right)$ methods. The obtained functions are referred to as relaxation dispersion curves. The applied radiofrequency field modulates the effect of chemical exchange on spin relaxation, i.e. analysis of relaxation dispersion data can provide insight in the chemical exchange kinetics [102, 104, 105, 114].

Spin relaxation measurements are in widespread use for characterization of dynamic aspects of protein function. Recent reviews identified several active research fields that greatly benefit from relaxation data analysis: proteinligand interactions, molecular recognition, enzyme catalysis, and protein folding [105, 115-117].

Residual dipolar couplings (RDCs) provide another precious source of dynamic information. RDCs represent averages over all orientations that are sampled by internuclear vectors over a relatively long time. Therefore, RDCs can report on conformational fluctuations occurring on time scales up to milliseconds [118]. Local dynamics in proteins have been elucidated by separately quantifying the order of individual, structurally well-defined fragments based on order matrix analysis with the smallest such fragment being the peptide plane [119]. Order parameters of bond vectors have been derived from RDCs by model-free approaches [120,121] or based on simple geometric models of peptide reorientation $[122,123]$. The comparison of order parameters obtained from relaxation measurements and RDC data provide insight into protein motions in the submicro- to millisecond range [118].

Exchange of amide protons with solvent water is traditionally being used to study stability of hydrogen bonds and to identify residues that are shielded from solvent. However, the technique can also yield information on conformational flexibility of the protein backbone on the millisecond to second time scale $[124,125]$. Amino acid-resolved hydrogen exchange techniques have provided detailed insight into structural features, thermodynamic stability, and kinetic rates of formation and decay of intermediate states during protein folding [126].

\subsection{Recent technological advances}

Methodological developments in NMR spectroscopy were facilitated by the continued efforts of instrument manufacturers to provide ever higher magnetic fields that increase sensitivity and resolution, innovative spectrometer electronics and more powerful computer equipment for storage and rapid processing of large data volumes. Commercially available high field magnets now 
cover the range up to $950 \mathrm{MHz}$ proton frequency, which is close to the optimum for certain TROSY applications (see Sect. 3). Introduction of cryogenic probe technology in the late 1990s allows up to fourfold increase in sensitivity without upgrading the field strength. Cryogenic cooling of the radiofrequency circuitry of the probe minimizes electronic noise while the protein sample is maintained at a higher temperature that is compatible with biological samples [127, 128].

Introduction of pulsed field gradients in connection with actively shielded gradient coils in high resolution probes in the early 1990s had a major impact on protein NMR [24]. Suppression of artifacts from non-ideal polarization transfer pathway selection had traditionally been achieved by phase-cycling, i.e. the pulse sequence is repeated many times but with systematically altered phases of the radiofrequency pulses. The phase cycle may become very complex for three- and four-dimensional NMR experiments. Complimentary use of pulsed field gradients for pathway selection drastically reduces the length of the required phase cycle [129]. Pulsed field gradients provide an effective means for suppression of the strong ${ }^{1} \mathrm{H}$ signal of solvent water. The WATERGATE scheme combines a selective radiofrequency pulse with a field gradient echo to refocus all signals except the water resonance [130]. Pulsed field gradient NMR represents also a powerful tool to study molecular diffusion in solution [131].

The long data acquisition times required for recording $3 \mathrm{D}$ or $4 \mathrm{D} \mathrm{NMR}$ spectra with uniform sampling of indirect time dimensions triggered considerable efforts to devise alternative protocols that provide the same spectral information in significantly shorter time [132,133]. In G-matrix FT NMR (GFT) spectroscopy a reduced dimensionality of the NMR experiment is accomplished by joint sampling of several indirect evolution periods, either exactly in step with one another or with suitable scaling factors between them [134]. Hadamard NMR spectroscopy replaces the indirect time domain evolution periods by direct frequency domain excitation of selected spins and requires prior knowledge of the resonance frequencies [135]. In projection-reconstruction NMR a properly chosen sparse set of time domain evolution data is recorded and subjected to Fourier transformation yielding projections of the multidimensional spectrum in frequency space. The full NMR spectrum is then reconstructed from these projections [136, 137]. The most rapid acquisition of 2D NMR spectra has been accomplished in a single-scan scheme where evolution and acquisition occur in the direct time dimension $[138,139]$. The traditional evolution in the indirect time domain is replaced by spatial encoding achieved by very strong pulsed field gradients in combination with selective RF pulses. The sample is divided into virtual slices along the $z$-axis which are individually addressed by the pulse sequence. This scheme has been extended to the acquisition of multidimensional NMR spectra within a fraction of a second [140]. 


\section{Deuteration and TROSY push the molecular weight limit of solution NMR}

The effective rotational correlation time, $\tau_{c}$, which characterizes the thermal motion of the biomolecule studied strongly increases with molecular weight or complex size. The resulting accelerated transverse spin relaxation causes severe line broadening with concomitant degradation of spectral resolution and sensitivity or even complete loss of NMR signals. Rapid transverse relaxation also limits the length of the pulse sequence that can be applied to the spin system and, in particular, may prevent efficient polarization transfer. Primarily this rapid transverse relaxation in large protonated proteins effectively restricts the applicability of conventional NMR pulse schemes discussed above to molecules smaller than $30 \mathrm{kDa}$.

Fractional or complete deuteration of non-exchangeable proton sites allows to extend the size limit [141, 142]. Dipole-dipole couplings (DDC) are a major source of transverse relaxation in diamagnetic proteins. Replacement of non-labile protons with deuterons, which have a 6.5-fold lower gyromagnetic ratio than protons scales down DDC and thus reduces the adverse effects of diminished rotational molecular motion. Deuterium substitution of nonexchangeable proton sites leads to reduction in ${ }^{13} \mathrm{C}$ line width if ${ }^{2} \mathrm{H}$ decoupling is applied [143] and to narrower amide proton resonances [144]. Triple resonance pulse schemes have been developed for assignment of backbone and side chain heteronuclei in highly deuterated proteins [145]. Deuteration enabled solution NMR studies of large proteins and complexes with molecular weight between 40 and $60 \mathrm{kDa}$ [146-148].

Careful analysis of spin relaxation led to the introduction of a new class of transverse relaxation-optimized heteronuclear pulse schemes that push the size limit of solution NMR dramatically [14, 149, 150]. Transverse relaxation can be very different for the two doublet components observed for each spin in a system of two scalar-coupled spin $1 / 2$ nuclei $[151,152]$. This is due to non-equivalent polarization transfer pathways that give rise to the individual components. Moreover, a range of different physical interactions like DDC, chemical shift anisotropy (CSA), exchange processes, or interactions between nuclear and electron spins in paramagnetic proteins can contribute to nuclear spin relaxation. Potentially this allows for interference between different relaxation processes in a polarization transfer specific manner [153]. Under fortunate conditions such interference causes suppression or strong reduction of transverse relaxation for one of the doublet components. Transverse relaxationoptimized spectroscopy (TROSY) exploits interference between dominant relaxation mechanisms for construction of advantageous magnetization transfer pathways [14]. Exchange between multiplet components is minimized and only the component with the most favorable relaxation properties is retained in the spectra. The first TROSY applications used interference between DDC and CSA [14] or between two CSA interactions [154] for suppression of trans- 
verse relaxation in ${ }^{1} \mathrm{H}-{ }^{15} \mathrm{~N}$ spin pairs in amide moieties $[155,156]$ or in ${ }^{1} \mathrm{H}-{ }^{13} \mathrm{C}$ spin pairs in aromatic rings of protein side chains [157, 158]. Subsequent implementations of the TROSY principle exploit interference of DDC and CSA in ${ }^{13} \mathrm{C}-{ }^{13} \mathrm{C}$ spin pairs [159] or interference between nuclear ${ }^{15} \mathrm{~N}-{ }^{1} \mathrm{H}$ DDC and Curie spin relaxation of electrons in paramagnetic proteins causing "paramagnetically induced narrowing" [160]. The popular methyl-TROSY affords substantial improvements in spectral resolution and sensitivity for protonated protein side chain methyls in otherwise highly deuterated proteins based on mutual cancellation of intra-methyl ${ }^{1} \mathrm{H}-{ }^{1} \mathrm{H}$ and ${ }^{1} \mathrm{H}-{ }^{13} \mathrm{C}$ dipole-dipole relaxation interactions [161].

Highly efficient constructive use of interference between two relaxation mechanisms requires that the two competing interactions have similar magnitude and proper vectorial orientations. For example, the $B_{0}$ field-independent dipolar coupling between ${ }^{1} \mathrm{H}$ and ${ }^{15} \mathrm{~N}$ spins will match the size of the fielddependent CSA for both the ${ }^{1} \mathrm{H}$ and ${ }^{15} \mathrm{~N}$ spins in amide groups at a magnetic field strength corresponding to proton resonances near $1 \mathrm{GHz}$ [162]. Further, the main axes of both axially symmetric CSA tensors of ${ }^{1} \mathrm{H}$ [163] and ${ }^{15} \mathrm{~N}$ [164] are close to parallel with the internuclear ${ }^{1} \mathrm{H}_{-}{ }^{15} \mathrm{~N}$ vector, determining the DDC. This fortunate coincidence allows simultaneous utilization of the TROSY effect for ${ }^{1} \mathrm{H}$ and ${ }^{15} \mathrm{~N}$ spins in amide moieties. Since ${ }^{1} \mathrm{H}-{ }^{15} \mathrm{~N}$ DDC and CSA interactions are by far the dominating sources of nuclear spin relaxation in amide moieties introduction of suitable TROSY elements in heteronuclear correlation pulse sequences yields significant gains in resolution and sensitivity $[165,166]$.

The term TROSY refers to the use of cross-correlated relaxation for reduction of effective transverse relaxation rates during polarization evolution and data acquisition. Polarization transfer via scalar couplings by the INEPT sequence (insensitive nuclei enhanced by polarization transfer) [167] is another building block in common heteronuclear correlation-type experiments that is severely disabled by rapid transverse relaxation. The efficiency of INEPT falls off rapidly with molecular size and becomes a limiting factor around $100 \mathrm{kDa}\left(\tau_{\mathrm{c}} \sim 70 \mathrm{~ns}\right)$ [149]. In contrast, cross-relaxation-induced polarization transfer (CRIPT) [168], which also exploits relaxation interference, allows magnetization transfer at a level that is independent of molecular size [169]. Although CRIPT is impractical for small molecules with short $\tau_{c}$, it is superior to INEPT for magnetization transfer in ${ }^{15} \mathrm{~N}-{ }^{1} \mathrm{H}$ moieties of large molecules with $\tau_{\mathrm{c}}>100 \mathrm{~ns}$ at high field strength around $1 \mathrm{GHz}$ proton frequency [170]. In case of intermediate rotational correlation times cross-relaxation-enhanced polarization transfer (CRINEPT) might be the method of choice. It combines INEPT and CRIPT elements and optimizes relaxation during magnetization transfer. CRINEPT should provide optimal polarization transfer efficiency for large molecules with intermediate $\tau_{\mathrm{c}}$ up to $300 \mathrm{~ns}$ [170].

Mutual cancellation of the dominant relaxation pathways by relaxation interference can drastically decrease transverse relaxation of selected spins. Further reduction is possible, if other relaxation pathways are disabled, most 
notably dipolar interactions with remote protons [149]. The most efficient line shape improvement by TROSY is reached with highly deuterated proteins. Site-independent uniform or partial deuteration of proteins can be achieved by protein expression in E.coli or yeast in $\mathrm{D}_{2} \mathrm{O}$-based media. Higher eukaryotic hosts may not tolerate high levels of $\mathrm{D}_{2} \mathrm{O}$ in the growth medium but deuteration can be accomplished by supplementing the culture medium with ${ }^{2} \mathrm{H}$-labeled amino acids or algal amino acid extracts $[13,171]$. Protons needed for NMR observation can be reintroduced by back-exchange of labile amide protons in $\mathrm{H}_{2} \mathrm{O}$-based buffers or incorporated during biosynthesis using dedicated isotope labeling schemes. Specific protonation of the side chains of selected amino acid types in otherwise deuterated proteins has been achieved by growing bacterial host cells in $\mathrm{D}_{2} \mathrm{O}$ media supplemented with protonated amino acids, amino acid precursors, or carbon sources [172-174].

In contrast to conventional triple resonance experiments the multiplet components of spin-spin correlations are not merged into a single peak by decoupling in TROSY-based schemes. Instead, only the narrow component is selected, e.g. by phase cycling or application of field gradients. Therefore, a key advantage of relaxation-optimized spectra is improved resolution. However, only 25 or $50 \%$ of the initial magnetization is preserved for detection [155] leading to reduced sensitivity at first glance. This is true for small molecules where differential line broadening is negligible. Beneficial use of TROSY elements requires large molecules and high fields where the greatly improved signal-to-noise ratio of the observed component overcompensates for the discarded fraction of polarization. Several mutually dependent factors determine the utility of a selected TROSY scheme, e.g. the type of relaxation interference employed, correlation time and isotope labeling characteristics of the molecule studied and the available field strength. As a rule of thumb, TROSY-based triple resonance experiments usually achieve an improved signal-to-noise ratio for doubly or triply labeled proteins or complexes above $20 \mathrm{kDa}[149]$.

The TROSY principle, i.e. the construction of transverse relaxationoptimized magnetization transfer pathways, has been incorporated into a large variety of multidimensional NMR pulse schemes to extend utility of solution NMR to studies of large molecules and complexes [150,175]. The use of TROSY elements for correlation of ${ }^{15} \mathrm{~N}$ and ${ }^{1} \mathrm{H}$ amide spins in combination with extensive deuteration slows down ${ }^{15} \mathrm{~N}$ and ${ }^{13} \mathrm{C}$ transverse relaxation rates, respectively, and provides large sensitivity gains in triple resonance experiments primarily used for protein backbone resonance assignment [165, 166, 176-179]. TROSY elements have been implemented in NOESY-type experiments which provide ${ }^{1} \mathrm{H}-{ }^{1} \mathrm{H}$ distances and supplement the sequential resonance assignment process in large proteins [154, 175, 180,181]. In addition to strongly reduced cross-peak line widths, TROSY elements also provide for artifact-free suppression of strong NOESY diagonal peaks thus avoiding interference with cross-peak integration $[182,183]$. Recently a methyl-TROSY 4D 
NOESY was reported that was acquired with sparse data sampling and allowed detailed analysis of an $82 \mathrm{kDa}$ protein [184]. NOE-based methyl-methyl distances provide extremely valuable structure restraints in protein studies [174]. Nevertheless, scarcity of NOESY-derived ${ }^{1} \mathrm{H}-{ }^{1} \mathrm{H}$ distances in highly deuterated molecules dictates the additional measurement of alternative restraints. Residual dipolar couplings of ${ }^{1} \mathrm{H}-{ }^{15} \mathrm{~N},{ }^{1} \mathrm{H}-{ }^{13} \mathrm{C},{ }^{13} \mathrm{C}-{ }^{13} \mathrm{C},{ }^{13} \mathrm{C}-{ }^{15} \mathrm{~N}$ spin pairs provide powerful global restraints for highly deuterated proteins (see Sect. 4). Incorporation of TROSY elements into HNCO-type triple resonance experiments allows detection of RDCs for large proteins [185-187].

Exploitation of the TROSY principle can largely uncouple the utility of solution NMR from the size of the molecule or molecular complex to be studied. In addition, exclusive isotope labeling of individual components or domains in large size molecular complexes or multidomain proteins, respectively, can be extremely beneficial for reduction of spectral complexity. Fragment labeling can be combined with heteronuclear spectral editing or isotope filtration $[188,189]$. Two strategies have been developed for segmental labeling of single chain proteins [190]. In both cases the fragments of the sequence are separately produced with the desired individual isotope labeling schemes. Subsequently the two fragments are combined either by native chemical ligation [191] or by intein-mediated peptide splicing [192].

Integration of TROSY and/or CRIPT/CRINEPT elements in NMR pulse schemes has not only drastically extended the size limit of liquid NMR but also expanded the scope of the technique to new areas in structural biology [193, 194]. Solution NMR is now capable of studying large membranespanning proteins in detergent micelles like the $\beta$-barrel outer membrane proteins OmpX [195], OmpA [196], and PagP [197] as well as diacylglycerol kinase with three helical transmembrane segments [198]. Solution NMR analysis of individual components and substrates of bacterial chaperonin complexes with total molecular weight up to $870 \mathrm{kDa}$ provide new insight in the protein folding process $[199,200]$. The protein-protein contact interface in a $120 \mathrm{kDa}$ macromolecular complex has been identified by combining a sophisticated isotope labeling strategy and TROSY-based pulse schemes [201]. The global backbone fold of a monomeric 723 residue enzyme of $82 \mathrm{kDa}$ has been obtained exclusively from solution NMR-derived restraints [202].

Application of the TROSY principle has extended the reach of dynamic studies to larger molecules. Favourable relaxation properties of backbone amide ${ }^{15} \mathrm{~N}-{ }^{1} \mathrm{H}$ groups [203, 204], of slowly relaxing methyl side chain groups [205-207], and of aromatic ring protons [208] have been exploited to design TROSY-based schemes to study dynamic properties of large particles [209]. Recent applications include studies on methyl side chain dynamics in the $82 \mathrm{kDa}$ enzyme malate synthase $\mathrm{G}$ [210], on conformational exchange in the $300 \mathrm{kDa} \mathrm{ClpP}$ protease complex [211] and on backbone dynamics of membrane proteins in micelles [212-214]. 


\section{Residual dipolar couplings provide global structure restraints}

Over the past ten years residual dipolar couplings (RDCs) evolved into one of the main sources of structural information available from solution NMR [215, 216]. The key advantage of RDCs is that they provide direct information on the orientation of internuclear vectors of the protein with respect to an external axis frame, i.e. they are truly long-range orientational restraints. RDCs are particularly useful for establishing the relative orientation of individual subunits in multidomain proteins and of components in multimolecular complexes where a sufficient number of long-range NOEs is rarely available. RDC take center stage in TROSY-based structure determination of very large proteins where NOE restraints are sparse due to extensive deuteration and rapid transverse relaxation.

The dipolar through space spin-spin coupling of two interacting nuclei depends both on length and orientation of the internuclear vector relative to the direction of the static magnetic field. However, rapid isotropic rotational diffusion of small and medium size molecules in solution completely averages the dipolar coupling to zero thus preventing extraction of the underlying structural information. Small residuals of the dipolar couplings may be observed in exceptional cases where the solute spontaneously shows anisotropic motion in the strong field of the NMR magnet, e.g. resulting from a pronounced asymmetry of the magnetic susceptibility of the solute [76]. However, widespread use of RDCs in NMR structure determination became possible only after the introduction of generally applicable concepts for weak protein alignment. Steric interaction of soluble proteins with a magnetic field-aligned very dilute and inert liquid crystalline lipid phase (bicelles) was shown to provide a tunable degree of solute alignment $[15,217]$. Partial alignment in suspensions of highly charged filamentous bacteriophage is mainly based on electrostatic interactions between the solute protein and the phage particles [218]. The different alignment mechanisms in phage and bicelles make these systems rather complementary to each other [219]. A large variety of additional $B_{0}$ field-dependent alignment media have been identified since then [215, 220]. Distinctly different alignment concepts are based on steric interactions of the solute with anisotropically compressed polyacrylamide gels [221,222] and on fusions of the target protein with lanthanide binding tags which allow to exploit the large magnetic susceptibility anisotropy of paramagnetic lanthanides for protein alignment [223-225].

Solute alignment should be sufficiently weak to ensure that only the strongest dipolar couplings give rise to observable RDCs in order to preserve the high resolution character of the NMR spectra and avoid an undue increase in spectral complexity. Reduction of dipolar couplings by motional averaging to about $10^{-3}$ of their static value is appropriate in most cases. RDCs between scalar-coupled spins manifest themselves in NMR spectra as additions to scalar 
couplings. Magnitude and sign of the RDC of scalar-coupled spins is derived from comparison of spectra recorded of weakly aligned and of isotropically tumbling protein. However, in the absence of a measurable scalar coupling only the magnitude of the RDC is obtained.

Solution NMR pulse schemes suitable for detection of scalar couplings are easily adapted for the measurement of RDCs. Both frequency-resolved schemes, where the coupling is derived from multiplet splittings and intensitybased methods, where the coupling is encoded in the NMR signal intensity via $J$ modulation [67] are in use [220]. For example, one-bond ${ }^{1} \mathrm{H}^{15} \mathrm{~N}$ and ${ }^{1} \mathrm{H}-{ }^{13} \mathrm{C}$ RDCs of small solutes may be derived from 2D HSQC experiments recorded in the absence of decoupling in the indirect dimension. However, the twofold increase in the number of peaks in comparison to a decoupled HSQC worsens spectral overlap for larger proteins. Spectral crowding can be reduced by the use of spin state-selective pulse schemes that generate subspectra which contain only one of the doublet components [226-230]. Heteronuclear 3D NMR experiments recorded without decoupling in the dimension of interest also alleviate spectral overlap, but extraction of precise couplings from the indirect dimension may necessitate very long acquisition times [186, 231]. Determination of RDCs from $J$ modulation experiments does not require such high spectral resolution and may therefore be more efficient [232, 233]. Use of the TROSY methodology allows to measure RDCs of very large molecules [185, 234, 235].

Besides one-bond ${ }^{1} \mathrm{H}_{-}{ }^{15} \mathrm{~N}$ and ${ }^{1} \mathrm{H}^{13} \mathrm{C}$ couplings a diverse range of other RDCs have been measured including backbone ${ }^{1} D_{\mathrm{N}-\mathrm{C}},{ }^{1} D_{\mathrm{N}-\mathrm{C} \alpha},{ }^{1} D_{\mathrm{C} \alpha-\mathrm{C}}$, ${ }^{1} D_{\mathrm{C} \alpha-\mathrm{C} \beta},{ }^{2} D_{\mathrm{N}-\mathrm{C} \alpha},{ }^{2} D_{\mathrm{HN}-\mathrm{C}},{ }^{2} D_{\mathrm{HN}-\mathrm{C} \alpha},{ }^{3} D_{\mathrm{HN}-\mathrm{C} \alpha}$ and side chain ${ }^{1} D_{\mathrm{H}-\mathrm{C}},{ }^{2} D_{\mathrm{H}-\mathrm{H}}$, and ${ }^{1} D_{\mathrm{C}-\mathrm{C}}$ couplings (the coupled spins and the number of bonds in-between are specified as sub- and superscript, respectively). Triple resonance NMR experiments allow determination of qualitatively different types of RDCs from a single 2D or 3D data set [234]. Very weak couplings may be resolved by using the E.COSY principle [66].

RDCs restrict the orientation of internuclear vectors with respect to a common reference frame. In order to access this geometric information one first needs to know the magnitude and rhombicity of the molecular alignment tensor [15] or alternatively some equivalent mathematical description of the weak protein alignment [216]. The components of the alignment tensor can be derived from a histogram representation of a large set of measured one-bond backbone RDCs of a protein, provided all bond lengths are essentially known, the bond vectors sample all orientations in space with roughly equal probability, and the generalized order parameter for internal motions of the considered backbone bond vectors shows a sufficiently narrow distribution [236].

RDCs are most commonly used to supplement other types of structure restraints in protein structure refinement. For example, an RDC-based quadratic harmonic potential has been included in the potential energy function that is 
used in MD-based structure calculation in the program XPLOR-NIH [86] and similar potentials are used in other structure generation software. Supplementing traditional NMR-based conformational restraints with RDCs improves precision and Ramachandran score of the calculated structures [237].

RDCs are uniquely suited for specifying the mutual orientation of subunits in large proteins or molecular complexes. Alignment tensors are usually determined separately for each fragment. The relative orientation of the components can then be obtained by rotating the tensors frames until they coincide, provided the two subunits do not show any significant rigid body motion with respect to each other. Prior knowledge of the subunit structure, e.g. from X-ray diffraction or separate NMR studies, will speed up structure determination and allows identification of conformational changes induced by the interaction. At least a small set of interfragment NOEs or other distance-dependent restraints is required in addition to the RDCs to fix the translational distance between the components, which can be achieved with rigid-body simulated annealing [238]. RDC-based methodology was used to study a large two-domain molecular chaperone [239] and very large protein-protein complexes [240]. The approach is not applicable if the dynamic properties of the individual fragments are not equivalent, e.g., due to qualitatively different interactions of the domains with the alignment medium in combination with a flexible linker between the domains [241]. However, in such cases it is very likely that the alignment tensors and RDC histograms of the two fragments are significantly different [242].

Alternative algorithms have been developed which base protein backbone structure determination almost exclusively on RDCs. If large sets of backbone RDCs are available the well-defined geometry of the peptide plane can serve as a starting point to screen for torsion angles $\varphi$ and $\psi$, specifying the relative orientation of consecutive peptide planes that are in agreement with the measured RDCs. Both the backbone structure of protein fragments consisting of multiple amino acids and the corresponding alignment tensors are determined in parallel using iterative algorithms. Protein tertiary structure is assembled on the premise of coinciding alignment tensors and refined against all measured RDCs [216, 243-246]. A low resolution initial backbone fold may also be obtained by searching a large database (e.g. the PDB) for homologous structures that allow close reproduction of the measured RDCs [247]. RDC-based molecular fragment replacement is conceptually similar but more generally applicable [248-250]. All measured one-bond backbone RDCs within a sliding frame of usually 7 to 10 residues are fitted against synthetic RDCs of all fragment structures in a comprehensive database. Torsion angles $\varphi$ and $\psi$ of a representative number of fragments that best fit the experimental RDC data are collected for each dipeptide junction of the target protein. Statistic evaluation of this ensemble of $\varphi$ and $\psi$ values allows identification of residue pairs with unambiguous torsion angles, which are then assembled into larger protein backbone fragments [248]. 


\section{Exploring protein-ligand interactions by solution NMR}

Complex biological processes rely on specific interaction of proteins with other polypeptides like receptors in signal transduction, chaperons in protein folding, or antigens in immune defense, with nucleic acids during gene transcription and translation, with complex carbohydrates in cell recognition, but also with small molecules like hormones, substrates, or drugs. A detailed understanding of biological function at the molecular level clearly requires in depth interaction analysis not only from a structural point of view but also with regard to specificity, strength and mechanism of the interaction. Dynamic aspects certainly play a crucial role in molecular recognition.

NMR spectroscopic analysis of complex formation goes far beyond a static "picture" of the 3D structure of tightly bound complexes. Solution NMR is in the unique position to probe both protein structure and dynamics at atomic resolution. NMR is sensitive to dynamic processes occurring over a wide range of time scales from picoseconds to seconds. Taken together this makes NMR a powerful and versatile tool to study molecular processes. Interactions with binding affinities in the nano- to millimolar range are accessible using a diverse collection of NMR techniques. NMR parameters utilized for interaction analysis include chemical shift, spin relaxation rates, translational diffusion rates, cross-relaxation rates, and saturation transfer phenomena [251, 252]. A prominent strength of NMR is the ability to closely monitor binding of a ligand to a receptor. In contrast to most other techniques, NMR is also sensitive to transient and dynamic aspects of interactions and to low affinity binding.

In what follows NMR-based protein interaction studies are subdivided into three major groups. They aim at i) structure analysis of the bound complex, ii) delineation of the interaction site on one or both molecules, iii) identification of interaction partners from a compound library. Some of the techniques discussed can address more than one of these aspects. Additional information is often available if NMR parameters are used to follow a titration analysis.

\subsection{Structure of protein complexes}

\subsubsection{High affinity complexes}

Structure determination of high affinity protein-protein or protein-ligand complexes is very similar to the study of single chain proteins if the complex is stable on the timescale of the NMR experiment. This regime is referred to as slow exchange. The stoichiometry of the interaction partners in the sample and/or the isotope labeling scheme can be chosen such that only NMR signals of bound molecules are observed. However, large overall size of the complex might restrict the choice of the NMR pulse scheme and lead to very complex spectra. TROSY-based experiments have been implemented to study large complexes [240]. 
Spectral crowding can be addressed by appropriate isotope labeling in combination with spectral editing or isotope filtering. These techniques allow discrimination between protons of the same type $\left(e . g .{ }^{1} \mathrm{H}^{\mathrm{N}}\right.$ or $\left.{ }^{1} \mathrm{H}_{\alpha}\right)$ based on their directly attached heteronuclear isotope $\left({ }^{14} \mathrm{~N}\right.$ or ${ }^{15} \mathrm{~N},{ }^{12} \mathrm{C}$ or $\left.{ }^{13} \mathrm{C}\right)$. The term spectral editing is used if protons bound to ${ }^{13} \mathrm{C}$ or ${ }^{15} \mathrm{~N}$ are selected for observation, while isotope filtering refers to pulse schemes that selectively suppress ${ }^{13} \mathrm{C}$ - or ${ }^{15} \mathrm{~N}$-bound protons in the recorded spectrum [253]. Spectral editing/filtering can be used to exclusively observe NMR signals of one of the interacting molecules or to discriminate between intra- and intermolecular NOEs $[254,255]$. Filtering can be achieved based on spin echo difference or half-filter methods [256] or on heteronuclear purge pulse schemes that form low pass ${ }^{1} \mathrm{H}-\mathrm{X}$ scalar coupling filters [257]. Very efficient selection of intermolecular ${ }^{1} \mathrm{H}-{ }^{-1} \mathrm{H}$ NOEs between a uniformly $\left({ }^{13} \mathrm{C},{ }^{15} \mathrm{~N}\right)$-labeled protein and an unlabeled partner was demonstrated with adiabatic ${ }^{13} \mathrm{C}$ inversion pulses [258]. The mentioned strategies allow separate assignment and initial structure calculation for the components of a bound complex using simplified spectra while addressing the structure of the entire complex at a later stage. Isotope labeling of non-protein ligands might require expensive special synthesis or might even be impractical. Nevertheless, appropriate editing or filtering schemes can provide separated NMR spectra even in the absence of isotope-labeled ligand.

Cross-saturation in combination with TROSY detection and an optimized isotope labeling scheme has been used to identify contact residues in stable, large protein-protein complexes $[259,260]$. Aliphatic protons in a non-isotopelabeled large protein are saturated by a band-selective decoupling scheme. Saturation spreads almost instantaneously to aromatic and amide protons due to intramolecular spin diffusion. The other interaction partner is produced with uniform ${ }^{15} \mathrm{~N}$ and ${ }^{2} \mathrm{H}$ labeling. Nevertheless, ${ }^{1} \mathrm{H}-{ }^{15} \mathrm{~N}$ correlations are observed for exchangeable hydrogen sites in a ${ }^{2} \mathrm{H}_{2} \mathrm{O} /{ }^{1} \mathrm{H}_{2} \mathrm{O}$ mixture in the absence of binding. Saturation of proton resonances of the unlabeled protein after formation of the complex will be transferred exclusively to those amide protons of the isotope-labeled binding partner that are in intimate contact with saturated spins. Intramolecular spin diffusion between isolated amide protons in the isotope-labeled protein is negligible due to the low proton density. Only the directly affected signals will disappear in the ${ }^{1} \mathrm{H}-{ }^{15} \mathrm{~N}$ correlation spectrum due to cross-saturation.

Alternatively, the effect of complex formation on the proton-deuterium exchange kinetics of amide hydrogens [261] and the chemical shift perturbation (CSP) technique $[262,263]$ have been used for mapping binding sites in stable complexes (Fig. 8). A combinatorial CSP approach can unravel contact sites even in the absence of resonance assignment, provided several samples are prepared with one interaction partner bearing ${ }^{15} \mathrm{~N}$ labels in one or a few selected types of amino acids [264]. Differential broadening of resonance lines of small or moderately sized molecules is observed upon strong binding to a large interaction partner. Enhanced broadening indicates resonances in the contact 

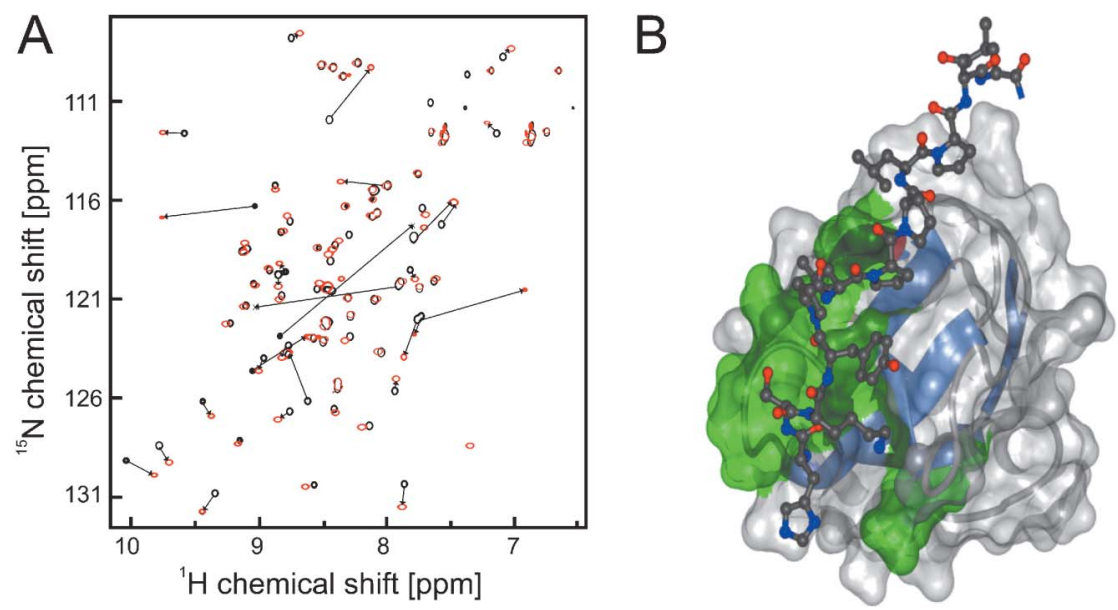

Fig. 8. Chemical shift perturbation mapping of human Hck SH3 domain residues involved in binding to a 12 residue peptide. A: Superposition of ${ }^{1} \mathrm{H},{ }^{15} \mathrm{~N}-\mathrm{HSQC}$ spectra of ${ }^{15} \mathrm{~N}$ isotope-labeled Hck SH3 recorded in the absence (black) and with an equimolar amount (red) of peptide. Titration of Hck SH3 with peptide (not shown) results in a stepwise disappearance of some of the free state signals in parallel with the appearance of new resonances. The new signals progressively increase in intensity and arise from the bound state protein conformation. This behavior indicates an exchange of the peptide between free and bound state that is slow compared to the observed difference in chemical shift. Arrows indicate the most pronounced resonance displacements. Residues with substantial chemical shift changes very likely belong to the peptide-binding site of the Hck SH3 domain. B: Ribbon and surface diagram of the high resolution structure of human Hck SH3 in complex with the artificial peptide ligand (PDB entry 2A4Y). The surface of residues that show the most prominent chemical shift changes upon peptide binding are colored in green. The bound peptide is shown in a ball and stick representation. The NMR structure of the complex is based on 354 inter- and 2146 intramolecular NOE-derived ${ }^{1} \mathrm{H}-{ }^{1} \mathrm{H}$ distances [H. Schmidt \& D. Willbold, submitted for publication].

interface [265, 266]. Relaxation properties and line shape of ${ }^{13} \mathrm{CH}_{3}$ resonances that are located in the contact interface change drastically in the presence of a protonated versus fully deuterated interaction partner. Recently, this effect was used to map the contact interface of a $120 \mathrm{kDa}$ complex by methyl-TROSY interaction spectroscopy [201].

\subsubsection{Low affinity complexes}

We distinguish weakly bound complexes where the interaction partners have approximately equal size (e.g. two proteins) from complexes where one partner (referred to as target protein) is much larger than the other one (referred to as ligand). At typical protein concentrations feasible in solution NMR (about 0.1 to $1 \mathrm{mM}$ ) and a dissociation constant of the complex in the high micro- to milli- 
molar range there will always be a mixture of complex with free protein and ligand in the NMR sample. In case of weakly bound protein-protein complexes it is difficult to distinguish the NMR signals of the bound from those of the free molecules. Also the low concentration of complex may pose a sensitivity problem. Nevertheless, very recently it was demonstrated that intermolecular NOEs of ultraweak protein-protein complexes can be obtained by appropriate isotope labeling schemes in combination with spectral editing/filtering and by boosting NMR sensitivity based on highest magnetic field strength and cryogenically cooled probes $[267,268]$. The approach provides detailed structural information on the protein-protein interface that is highly valuable for datadriven protein docking or structure prediction.

Reversible protein-ligand complexes are very attractive for determination of the protein-bound structure of the ligand. A large difference in the size of target and ligand translates into very different rotational correlation times, auto- and cross-relaxation rates, as well as translational diffusion rates of the small ligand as compared to target protein or bound complex. NMR spectra of the free ligand may contain information on the bound ligand structure provided association and dissociation of the complex is rapid on the relevant NMR time scale. Such techniques may be referred to as exchange-based methods.

The transferred nuclear Overhauser effect (TrNOE) is the most prominent example of this class of experiments [269-271]. It is essential that the rotational correlation time of the complex is drastically longer than that of the free ligand. Since solution NMR spectra are recorded on the free ligand there is basically no upper limit on the size of the target protein. However, the observed NOEs reflect the residence time-weighted average over the cross-relaxation in the free and bound state, respectively. Efficiency of cross-relaxation is much higher in the slowly tumbling complex compared to a rapidly moving small molecule, i.e. the observed NOESY cross-peak intensity arises mainly from cross-relaxation in the bound state. TrNOE experiments are typically conducted with a large excess of ligand over target protein (10- to 50-fold), the rapid exchange of the ligand on and off the binding site provides a means of chemical amplification of the NMR signals. Of course, the residence time of the ligand in the bound state must be short compared to transverse relaxation in order to retain sufficient transverse magnetization for detection on the free ligand. Reduced rotational diffusion causes extensive broadening of target protein signals, perhaps even beyond detection. Alternatively, a relaxation filter element can be added to the pulse sequence to selectively weaken target protein signals [272].

Another structure-related NMR observable that strongly depends on rotational correlation time is cross-correlated relaxation (CCR) [273]. The CCR phenomenon is the result of relaxation interference (e.g. dipolar- or CSAbased) and is sensitive to the projection angle between the vectors defined by the two interfering relaxation processes [68]. Transferred CCR provides angu- 


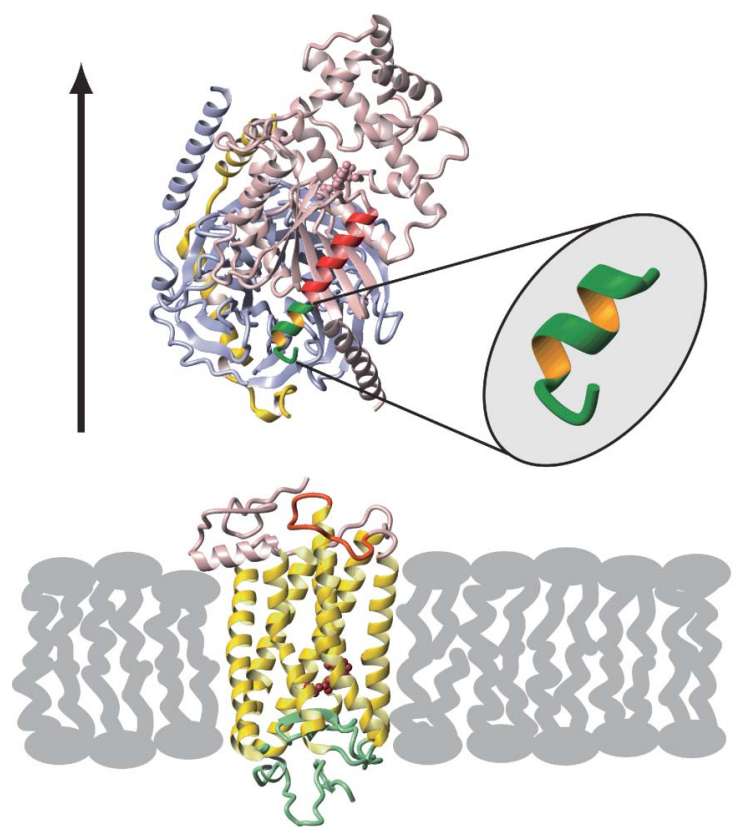

Fig. 9. Structure and orientation of a transducin peptide fragment in the rhodopsinbound state derived from TrNOEs and TrDCs [279]. X-ray structures of free transducin (above) [280] and ground state rhodopsin (below) [281] are shown. The insert depicts an enlarged representation of the bound peptide. The orientation of the peptide with respect to the membrane normal (arrow) is precisely defined by the measured TrDCs. The peptide corresponds to the 11 carboxy-terminal amino acid residues of the $\alpha$ subunit of transducin, which are largely undefined in the crystal structure. In the figure this region is replaced by the NMR structure of the peptide (green/gold) observed upon peptide binding to photoactivated rhodopsin using a docking procedure. Binding is likely to induce elongation of helix $\alpha 5$ (red) of the $\alpha$ subunit of transducin. The axis of the helix is tilted by about $40^{\circ}$ relative to the membrane normal. The peptide binds most likely to a site on the third cytoplasmic loop of photo-activated rhodopsin (orange) [282]. (reproduced from [278] with kind permission of Wiley-VCH).

lar information on the target-bound conformation of small molecules in rapidly exchanging complexes of large target and small ligand molecules [274-276].

Nuclear dipole-dipole couplings can be as large as several $\mathrm{kHz}$ in molecules that are strongly aligned with respect to the magnetic field, $B_{0}$, depending on the gyromagnetic ratios of the nuclei and the length, dynamics, and orientation with respect to $B_{0}$ of the internuclear vector. In contrast, dipolar couplings of small, isotropically tumbling molecules average to zero. Transferred dipolar couplings (TrDCs) can be measured on the free ligand in case of rapid exchange of the ligand between a target-bound, macroscopically aligned state and the free form in solution [277]. Measured TrDCs are a residence time-weighted average of the couplings in the two states and 
contain valuable information on structure and orientation of the target-bound ligand [278]. TrDCs in concert with TrNOEs have been used to determine the high resolution structure of a peptide bound to photo-activated rhodopsin, a $G$ protein-coupled receptor, in its natural membrane environment [279] (see Fig. 9).

The cross-saturation technique has been extended to precise interface mapping of large complexes in the fast exchange regime [283]. Transferred crosssaturation studies determined the binding epitope of proteins that transiently bind to a membrane protein [284] or to phospholipids vesicles [285].

\subsubsection{Data-driven docking}

The number of solved high resolution X-ray and NMR structures of individual biological macromolecules is much higher than that of complex structures. In light of ongoing structural genomics efforts this picture is not likely to change in the near future. Given the complexity and large efforts required for a full de novo determination of complex structures it appears prudent to use docking approaches that combine previous knowledge of the structure of individual components with biochemical (e.g. mutagenesis) or biophysical data (e.g. intermolecular NOEs, interface mapping, RDCs, ${ }^{15} \mathrm{~N}$ relaxation data) $[286,287]$. Data-driven docking is much faster than the complete NMR structure determination of a complex. Moreover, docking approaches allow for structural studies of transiently forming or weakly bound complexes which are not directly accessible by most other methods but are fundamentally important in numerous biological processes.

Docking of protein-protein complexes relies on availability of high quality NMR or X-ray structures of the unbound proteins and the premise that the backbone conformation of the two partners does not change significantly upon complexation. Experimental restraints on both the translational distance and the relative orientation of the proteins in the complex are needed for high fidelity docking. Accurate docking was demonstrated for a $40 \mathrm{kDa}$ complex based on rigid body minimization using a sparse set of NOE-derived intermolecular ${ }^{1} \mathrm{H}-{ }^{1} \mathrm{H}$ distances and one-bond backbone RDCs in addition to the X-ray structures of the free proteins [288]. Alternatively, CSP data and chemical shift simulations [289] have been used in combination with RDCs to restrain protein-protein complexes [290]. The docking program TreeDock conducts an exhaustive search of configurational space based on the condition that two selected atoms (anchors), one from each molecule, must be in contact. The choice of anchor pairs is guided by experimental CSP, intermolecular NOE, or mutagenesis data [291]. In the NMR-driven HADDOCK approach CSP or other experimental intermolecular contact information is converted into ambiguous interaction restraints (AIRs) which are then employed in protein-protein docking using rigid body minimization in combination with semi-flexible simulated annealing refinement [292]. Recently, AIRs were supplemented with RDCs 
in the docking procedure [293] and the resulting complex structures were cross-validated using orientation-dependent ${ }^{15} \mathrm{~N}$ relaxation data [286]. Similarly, structural models of a molecular complex obtained by docking of known substructures have been filtered and ranked a posteriori based on compliance with experimental CSP [294] and RDC data [295].

\subsection{Localization of interaction sites}

The major aim of many studies on protein interactions with ligands or other small molecules is delineation of the interaction site on one or both components. Several NMR-based techniques (cross-saturation, differential line broadening) that address this issue have already been introduced in the previous paragraph. Here we focus exclusively on chemical shift perturbation, H/D exchange, and paramagnetic probes for mapping of contact sites.

\subsubsection{Chemical shift perturbation (CSP) mapping}

The most frequently used NMR method for mapping protein-ligand interactions to the surface of a target protein is based on chemical shift changes resulting from complex formation [296]. The ligand can be of any kind, e.g. an ion, a small molecule, or a large protein, as long as the NMR signals of the target protein are easily detectable. Typically a series of ${ }^{1} \mathrm{H},{ }^{15} \mathrm{~N}-\mathrm{HSQC}$ spectra of ${ }^{15} \mathrm{~N}$-labeled target protein is recorded with increasing amounts of non-labeled ligand. Chemical shifts of nuclei close to the binding interface are very likely perturbed by the presence of the ligand. Provided resonance assignment has been completed, CSP data map the binding site to the amino acid sequence, or onto the $3 \mathrm{D}$ structure of the target, if known. ${ }^{1} \mathrm{H},{ }^{13} \mathrm{C}-\mathrm{HSQC}$ experiments are also very sensitive to environmental changes of nuclei at the binding site [297]. Use of cryogenic probe technology at high field strength allows ${ }^{1} \mathrm{H},{ }^{13} \mathrm{C}$-HSQC-based CSP mapping at natural ${ }^{13} \mathrm{C}$ abundance if ${ }^{13} \mathrm{C}$ labeled protein is not available. Chemical shift mapping is not restricted to the contact site on the target protein. Instead, nuclei of both interaction partners directly involved in binding can be identified by the CSP methodology, provided appropriate isotope labeling schemes and/or NMR experiment combinations are chosen. CSP-based delineation of contact surfaces might be challenging in the presence of allosteric effects [298] or even impossible if extended conformational changes of the target occur upon binding. In both cases chemical shifts of nuclei far away from the binding site may change, too.

HSQC-based NMR titrations do not only unravel the contact sites but may in addition allow estimates on strength, stoichiometry, specificity, and kinetic aspects of the interaction [296]. The kinetics of binding can be classified based on the overall spectral changes observed during titration. If complex dissociation is fast on the chemical shift and spin-spin relaxation time scales, only a single correlation is observed for each pair of directly bound ${ }^{1} \mathrm{H}-\mathrm{X}$ spins in 

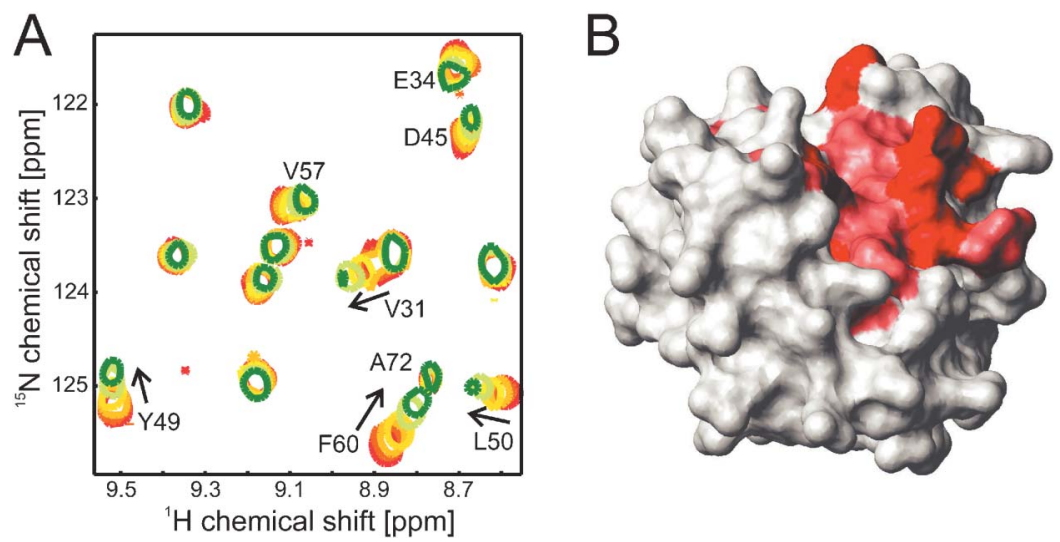

Fig. 10. Analysis of GABARAP-peptide interaction by HSQC titration. A: Superposition of a selected region of HSQC spectra obtained upon titration of GABARAP with increasing amounts of a peptide ligand (from red over yellow to green). Only ${ }^{1} \mathrm{H}-{ }^{15} \mathrm{~N}$ correlations of the ${ }^{15} \mathrm{~N}$-labeled GABARAP are visible. HSQC peaks that show substantial chemical shift changes are annotated. The chemical environment of the corresponding nuclei changes due to peptide binding. The gradual shift of resonances indicates fast exchange of the ligand on and off the binding site. B: Surface representation of the NMR structure of GABARAP. Residues with pronounced chemical shift changes due to peptide binding are colored in red. A continuous patch is obtained that aligns along a groove on the surface of GABARAP and most likely represents the peptide-binding site.

the HSQC. This situation is referred to as fast chemical exchange and is typically observed for low affinity binding. The corresponding chemical shifts are residence time-weighted averages of the shifts in the free and bound states, respectively. Peaks in the HSQC spectrum that belong to interface residues move gradually from free to bound state positions upon titration with ligand (see Fig. 10). In contrast, in case of slow chemical exchange, which is typically observed for strong binding with small dissociation rate constants, separate HSQC peaks are observed for free and bound interface residues (see Fig. 8). Titration with ligand causes decreasing and increasing intensities of free and bound state resonances, respectively. The intensity ratio of peak pairs that belong to the same site reflects the relative occupation of the two states. Detailed analysis of the exchange kinetics may require separate assignment of free and bound state resonances. Chemical exchange that is intermediate on the chemical shift time scale typically results in extensive line broadening or complete disappearance of NMR signals of nuclei that are located in the interface.

Ring currents have a pronounced effect on the chemical shift of nearby nuclei. If the ligand contains aromatic ring systems, $j$ surface analysis of CSP data may allow very precise mapping of the binding site on the surface of the target as demonstrated for ligand binding to HCV NS3 helicase and protease [299]. 


\subsubsection{Interface mapping by hydrogen exchange}

Amide protons involved in stable hydrogen bonds are largely protected from hydrogen exchange with solvent water. This allows identification of stably folded sequence stretches in proteins or of protein regions that are buried in a hydrophobic environment like a micelle [300]. Ligand binding has a pronounced effect on $\mathrm{H} / \mathrm{D}$ exchange rates of amide protons in the interface region. A strong decrease of $\mathrm{H} / \mathrm{D}$ exchange rates upon binding delineates the binding interface in tightly bound complexes [261,301]. However, overall reduction in conformational exchange due to complex formation might alternatively cause changes of $H / D$ exchange rates that are not restricted to the immediate contact site but rather observed throughout the target protein [302, 303].

\subsubsection{Interface mapping with paramagnetics}

Paramagnetic ions in solution or spin labels that are covalently attached to a molecule of interest contain unpaired electrons with a very large gyromagnetic ratio. They dramatically broaden resonance lines of vicinal nuclear spins in a distance-dependent manner. Spin labels have been successfully applied to measure relatively long distances, dynamic properties, or surface accessibility. Relaxation enhancement of solvent-exposed amide protons due to elevated levels of paramagnetic oxygen in the solvent was exploited to map protein-protein interaction sites [304]. Reduction of spin-lattice relaxation rates upon complex formation reveals residuespecific protection from solvent and paramagnetic agent [305]. Spin-labeled amphipathic molecules that contain unpaired electron moieties at different positions along an aliphatic chain have been introduced into micelles to probe the location of incorporated peptides [306]. One of two interacting molecules can be spin-labeled in a site-directed manner by attachment of a paramagnetic nitroxide probe to a unique cysteine sulfhydryl group, which may be either naturally present or engineered by mutagenesis. A peptide antigen covalently bound to the spin label TEMPO (2,2,6,6-tetramethyl-piperidine-1-oxyl) was used to map out the binding region on a Fab antibody fragment [307]. Peptide-attached TEMPO enabled identification of peptide-binding sites on the surface of a chaperone protein [308]. Spin-labeled peptide was titrated into a solution of ${ }^{15} \mathrm{~N}$-labeled chaperone and the disappearance of resonances from the binding region was monitored with ${ }^{1} \mathrm{H},{ }^{15} \mathrm{~N}$-HSQC spectra.

Changes of NMR resonance positions are observed for nuclear spins in the vicinity of a paramagnetic center that may be present in metalloproteins or introduced via spin labels. These chemical shift changes are referred to as pseudocontact shifts [82]. Intermolecular pseudocontact shifts were used to specify the contact interface and relative position of two redox proteins in a transient complex [309]. 


\subsection{Ligand screening by NMR}

NMR screening of compound libraries is now one of the established methods for inhibitor design and drug lead generation in pharmaceutical research [310312]. NMR is in the unique position to identify weakly binding ligands and to provide structural details that may aid in rational design of potent drug leads based on the initial hits. A diverse array of NMR-based methods has been developed which allow selection of ligands out of a large compound library that bind to a given receptor. One of the first implementations of NMR screening is based on chemical shift perturbation in heteronuclear 2D NMR spectra of isotope-labeled receptor upon addition of test compound mixtures. Low affinity ligands identified this way can be optimized and linked together to produce a high affinity ligand, an approach known as "SAR by NMR" [313].

Many of the established screening methods rely on observation of the small ligand molecules which yield relatively simple NMR spectra [314]. Ligand-based methods are restricted to transient binding. They usually work at relatively low receptor concentrations and do not require isotope labeling. Screening methods monitor NMR observables that drastically change upon binding of the ligand to a large receptor. Small molecules exhibit slow relaxation rates $\left(R_{1}, R_{2}\right)$, vanishing or weak 2D-NOESY cross-peaks, and large translational diffusion rates. In contrast, large receptor molecules and receptor-bound ligands show fast relaxation rates, strong 2D-NOESY crosspeaks that have the same sign as the diagonal peaks, and smaller translational diffusion rates. Binding can also be verified by observation of ${ }^{1} \mathrm{H}$ magnetization transfer from receptor to ligand, which only occurs for molecules intimately bound to the receptor and requires some minimum life time of the bound complex. A disadvantage of ligand-based methods is the lack of information on the location of the ligand-binding site on the receptor, which complicates the design of potent drug leads by covalently linking ligands that weakly bind to proximal sites on the target. Second-site screening techniques partially address this issue [315]. The need for high ligand concentrations might pose a solubility problem and may result in false hits due to unspecific binding. Finally, techniques that are based on transient binding may fail to detect strongly binding ligands due to complete relaxation of the ligand magnetization in the bound state. Binding assays that exploit competition with previously identified ligands to the same site can avoid this problem [316]. In the following we will briefly introduce the most common approaches for ligand-based screening of compound libraries for receptor binding.

\subsubsection{Transverse relaxation enhancement}

Transient binding to a large receptor increases the apparent transverse relaxation rate $\left(R_{2}\right)$ of ligand spins and is reflected in line broadening. The extent of the effect depends on the relative size of ligand and receptor, binding affin- 
ity, ligand-to-receptor ratio, and the exchange kinetics. Binding may be verified by line shape inspection or measurement of $R_{2}$ or $R_{1 \rho}$ rate constants [128]. Screening is typically done with large excess of ligand resulting in vanishingly weak NMR signals of the receptor. Translational diffusion-based filter elements may be added to the pulse sequence to reduce or suppress NMR signals of rapidly diffusing ligands which obviously lack any interaction with the large receptor [317].

Utility of transverse relaxation enhancement for compound library screening can be significantly improved by placing a paramagnetic spin label in the vicinity of the ligand-binding site. Following this strategy, spin-labeled first-site ligands were used to search for secondary ligands that bind in close proximity to the primary ligand [318]. Paramagnetic relaxation enhancement in combination with a relaxation filter completely eliminates ${ }^{1} \mathrm{H}$ NMR signals of second-site ligands in case of simultaneous binding with the spin-labeled compound. The strategy was later adapted for primary NMR screening by attaching the spin label directly to the receptor [319]. This approach requires some prior knowledge on the location of the ligand-binding site. The strong relaxation enhancement produced by the spin label allows performance of the binding assay at very low receptor concentration.

\subsubsection{Transferred NOEs}

Rapidly reorienting small molecules (typically up to $\sim 2000 \mathrm{Da}$ ) in solution show small positive or very weak intramolecular NOEs that slowly build up during the mixing time of a 2D NOESY experiment. Cross-relaxation in the receptor-bound state is rapid and results in large negative NOEs of the bound ligand which build up very quickly and are referred to as transferred NOEs (TrNOEs) [271]. The NOESY spectrum of a reversibly binding ligand recorded with short mixing time in the presence of a large receptor (at least $30 \mathrm{kDa}$ ) will be dominated by TrNOEs of the small ligand. Receptor signals will be barely visible due to large excess of ligand over receptor (typically 10- to 50-fold) and line broadening resulting from reduced reorientational motion of the receptor. Receptor signals may be further attenuated by relaxation filter techniques [272]. More importantly, NOESY cross-peaks of small compounds that do not bind to the receptor will remain vanishingly weak. This provides an excellent opportunity for screening of compound libraries for binding activity [320].

\subsubsection{Saturation transfer difference (STD) spectroscopy}

The STD technique is also based on rapid cross-relaxation of ${ }^{1} \mathrm{H}$ spins of large receptors and receptor-ligand complexes [314,321]. Selective saturation of a protein ${ }^{1} \mathrm{H}$ NMR signal will rapidly spread to all protons of the protein by intramolecular spin diffusion. In addition, intermolecular magnetization transfer will cause saturation of protons of those ligands that transiently bind to 


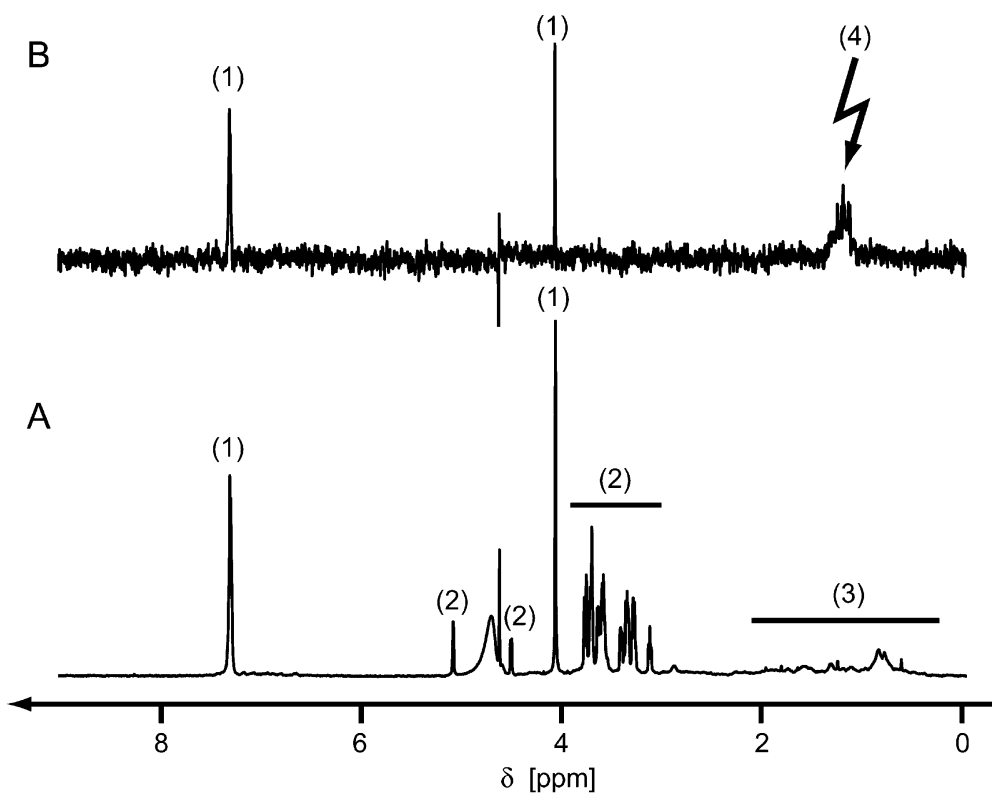

Fig. 11. Saturation transfer difference (STD) spectroscopy proves interaction of trypsin with benzylamine. A: ${ }^{1} \mathrm{H}$ NMR spectrum of a sample containing $2 \mathrm{mM}$ benzylamine (1), $2 \mathrm{mM}$ glucose (2), and $20 \mu \mathrm{M}$ trypsin (3) in ${ }^{2} \mathrm{H}_{2} \mathrm{O}$. Weak interaction of trypsin with benzylamine is known [325], glucose was added as negative control. B: Difference of ${ }^{1} \mathrm{H}$ NMR spectra recorded without and after selective saturation of protein resonances at $\sim 1 \mathrm{ppm}$ (4). Only benzylamine signals but not the glucose resonances are attenuated following saturation. Accumulation of 128 difference spectra clearly shows benzylamine signals (1). The spectral region around the saturation frequency (4) is slightly disturbed.

the receptor. The STD method does not require isotope labeling and is best suited for receptor concentrations in the low micromolar range, a large excess of potential binders (typically 50- to 100-fold), and a large difference in the size and rotational diffusion characteristics of receptor and ligand. A regular ${ }^{1} \mathrm{H}$ NMR spectrum of a receptor and a mixture of potential binders recorded without saturation will be dominated by the signals of the highly concentrated small molecules. In a second spectrum recorded after selective saturation of the receptor the NMR signals of the receptor and of receptor-binding ligand molecules will have diminished intensity. A difference spectrum calculated from these two 1D NMR spectra contains signals of positive binders only ( $c f$. Fig. 11). Irradiation for selective saturation of protein resonances must be confined to a spectral region that is devoid of ligand signals. During application of the selective pulse train, typically for several seconds, there is a rapid turnover of weakly binding ligand molecules on each receptor, i.e. the sample volume is 
constantly "pumped" with saturated ligand molecules. This pumping effect is responsible for the extraordinary high sensitivity of the STD approach which makes it very attractive for compound screening [314]. However, very tight binding will strongly reduce the turnover rate and may cause complete relaxation of ligand magnetization in the bound state, i.e. strong binders might go undetected. The STD approach has also been successfully applied to study binding of small molecules to an integral membrane protein [322], virus particles [323], and living cells [324]. The STD technique is easily adapted for use in 2D NMR pulse schemes [321].

The binding epitope of the ligand can be identified by STD NMR. Protons in immediate contact with the receptor experience the strongest saturation while protons further away from the contact site are less affected [321,326, 327]. Reliable interface mapping requires a relatively high off-rate of the ligand and a large excess of ligand over receptor. Widely different longitudinal relaxation rates of ligand protons [328] or non-uniform saturation of receptor resonances [329] may complicate the quantitative interpretation of differential saturation in terms of binding epitopes.

STD NMR benefits from a high proton density in the receptor which supports efficient saturation transfer. Target molecules with few protons may profit from a variant of the STD method named WaterLOGSY [330, 331]. Within this scheme the proton resonance of bulk water is either selectively saturated or inverted. Soluble proteins are surrounded by a layer of reversibly bound water. Efficient magnetization transfer between small water and ligand molecules is feasible only via binding to the large receptor. Observation of negative NOEs between ligand and water protons clearly indicates ligand binding to the receptor.

NMR spectroscopy has evolved into a valuable and powerful tool in biological, biomedical, and pharmaceutical research. We reviewed recent progress of liquid state NMR for structure determination of biological macromolecules and their complexes with ligands, for ligand screening, and for studies of dynamics of biomolecules. NMR data provide tremendous insights into the nature and function of proteins. Even the bare structure of a protein often allows prediction of protein function and is by far superior to methods that rely exclusively on sequence homology [332-336]. Still, the field of solution NMR is rapidly developing and expanding. Solid state NMR applications for biological research which are not covered in this review progress at an even faster pace and would certainly warrant another review.

\section{Acknowledgement}

The work presented in this review was supported in part by grants of the DFG to D. Willbold (Wi 1472/4-1, 4-2, 5-1, and 5-2) and B. W. Koenig (KO 2143/3-1 and 3-2). Holger Schmidt kindly provided the NMR spectra and structure of the peptide-human Hck SH3 complex shown in Fig. 8. 


\section{References}

1. K. Wüthrich, NMR of Proteins and Nucleic Acids. John Wiley \& Sons, New York (1986).

2. A. Bax and S. Grzesiek, in NMR of Proteins, G. M. Clore and A. M. Gronenborn (Eds.). CRC Press, Boca Raton (1993), p. 33.

3. J. Cavanagh, W. J. Fairbrother, A. G. Palmer, III, and N. J. Skelton, Protein NMR Spectroscopy. Academic Press, San Diego (1996).

4. K. Wüthrich, Biosci. Rep. 23 (2003) 119.

5. R. R. Ernst, Adv. Magn. Reson. 2 (1966) 1.

6. J. Jeener, unpublished lecture, Ampere Summer School, Basko Polje, Yugoslavia (1971).

7. W. P. Aue, E. Bartholdi, and R. R. Ernst, J. Chem. Phys. 64 (1976) 2229.

8. K. Nagayama, K. Wüthrich, P. Bachmann, and R. R. Ernst, Biochem. Biophys. Res. Comm. 78 (1977) 99.

9. R. R. Ernst, G. Bodenhausen, and A. Wokaun, Principles of Nuclear Magnetic Resonance in One and Two Dimensions. Clarendon Press, Oxford (1987).

10. G. M. Clore and A. M. Gronenborn, Science 252 (1991) 1390.

11. J. R. Martin, F. A. Mulder, Y. Karimi-Nejad, J. van der Zwan, M. Mariani, D. Schipper, and R. Boelens, Structure 5 (1997) 521.

12. G. M. Clore and A. M. Gronenborn, Curr. Opin. Chem. Biol. 2 (1998) 564.

13. K. H. Gardner and L. E. Kay, Annu. Rev. Biophys. Biomol. Struct. 27 (1998) 357.

14. K. Pervushin, R. Riek, G. Wider, and K. Wuthrich, Proc. Natl. Acad. Sci. USA 94 (1997) 12366.

15. N. Tjandra and A. Bax, Science 278 (1997) 1111.

16. A. Bax, Methods Enzymol. 176 (1989) 151.

17. A. Kumar, R. R. Ernst, and K. Wüthrich, Biochem. Biophys. Res. Comm. 95 (1980) 1.

18. M. Karplus, J. Am. Chem. Soc. 85 (1963) 2870.

19. M. P. Williamson, T. F. Havel, and K. Wuthrich, J. Mol. Biol. 182 (1985) 295.

20. R. Kaptein, E. R. Zuiderweg, R. M. Scheek, R. Boelens, and W. F. van Gunsteren, J. Mol. Biol. 182 (1985) 179.

21. G. M. Clore, A. M. Gronenborn, A. T. Brunger, and M. Karplus, J. Mol. Biol. 186 (1985) 435.

22. H. J. Dyson, G. P. Gippert, D. A. Case, A. Holmgren, and P. E. Wright, Biochemistry 29 (1990) 4129.

23. J. D. Forman-Kay, G. M. Clore, P. T. Wingfield, and A. M. Gronenborn, Biochemistry 30 (1991) 2685.

24. A. Bax, Curr. Opin. Struct. Biol. 4 (1994) 738.

25. G. Bodenhausen and D. J. Ruben, Chem. Phys. Lett. 69 (1980) 185.

26. A. Bax, R. H. Griffey, and B. L. Hawkins, J. Magn. Reson. 55 (1983) 301.

27. H. Oschkinat, C. Griesinger, P. J. Kraulis, O. W. Sorensen, R. R. Ernst, A. M. Gronenborn, and G. M. Clore, Nature 332 (1988) 374.

28. S. W. Fesik and E. R. P. Zuiderweg, J. Magn. Reson. 78 (1988) 588.

29. L. E. Kay, G. M. Clore, A. Bax, and A. M. Gronenborn, Science 249 (1990) 411.

30. M. Ikura, L. E. Kay, and A. Bax, Biochemistry 29 (1990) 4659.

31. M. Wittekind and L. Mueller, J. Magn. Reson. B 101 (1993) 201.

32. P. Leighton and P. Lu, Biochemistry 26 (1987) 7262.

33. D. C. Muchmore, L. P. McIntosh, C. B. Russell, D. E. Anderson, and F. W. Dahlquist, Methods Enzymol. 177 (1989) 44.

34. J. Sambrook and D. W. Russell, Molecular Cloning: A Laboratory Manual. Cold Spring Harbor Laboratory Press, Cold Spring Harbor (2001).

35. L. Hewitt and J. M. McDonnell, Methods Mol. Biol. 278 (2004) 1. 
36. Y. Laroche, V. Storme, J. De Meutter, J. Messens, and M. Lauwereys, Biotechnology (NY) 12 (1994) 1119.

37. A. R. Pickford and J. M. O'Leary, Methods Mol. Biol. 278 (2004) 17.

38. C. H. Klaassen, P. H. Bovee-Geurts, G. L. Decaluwe, and W. J. DeGrip, Biochem. J. 342 (1999) 293.

39. A. Strauss, F. Bitsch, G. Fendrich, P. Graff, R. Knecht, B. Meyhack, and W. Jahnke, J. Biomol. NMR 31 (2005) 343.

40. P. E. Coughlin, F. E. Anderson, E. J. Oliver, J. M. Brown, S. W. Homans, S. Pollak, and J. W. Lustbader, J. Am. Chem. Soc. 121 (1999) 11871.

41. D. R. Higgins and J. M. Cregg, Methods Mol. Biol. 103 (1998) 1.

42. T. Kigawa, T. Yabuki, Y. Yoshida, M. Tsutsui, Y. Ito, T. Shibata, and S. Yokoyama, FEBS Lett. 442 (1999) 15.

43. C. Klammt, F. Lohr, B. Schafer, W. Haase, V. Dotsch, H. Ruterjans, C. Glaubitz, and F. Bernhard, Eur. J. Biochem. 271 (2004) 568.

44. T. B. Acton, K. C. Gunsalus, R. Xiao, L. C. Ma, J. Aramini, M. C. Baran, Y. W. Chiang, T. Climent, B. Cooper, N. G. Denissova, S. M. Douglas, J. K. Everett, C. K. Ho, D. Macapagal, P. K. Rajan, R. Shastry, L. Y. Shih, G. V. Swapna, M. Wilson, M. Wu, M. Gerstein, M. Inouye, J. F. Hunt, and G. T. Montelione, Methods Enzymol. 394 (2005) 210.

45. N. A. Farrow, R. Muhandiram, A. U. Singer, S. M. Pascal, C. M. Kay, G. Gish, S. E. Shoelson, T. Pawson, J. D. Forman-Kay, and L. E. Kay, Biochemistry 33 (1994) 5984.

46. M. Sattler, J. Schleucher, and C. Griesinger, Prog. NMR Spectrosc. 34 (1999) 93.

47. G. W. Vuister and A. Bax, J. Am. Chem. Soc. 115 (1993) 7772.

48. S. Grzesiek, J. Anglister, and A. Bax, J. Magn. Reson. B 101 (1993) 114.

49. A. Bax, G. M. Clore, P. C. Driscoll, A. M. Gronenborn, M. Ikura, and L. E. Kay, J. Magn. Reson. 87 (1990) 620.

50. D. S. Wishart and B. D. Sykes, J. Biomol. NMR 4 (1994) 171.

51. S. Spera and A. Bax, J. Am. Chem. Soc. 113 (1991) 5490.

52. F. Delaglio, S. Grzesiek, G. W. Vuister, G. Zhu, J. Pfeifer, and A. Bax, J. Biomol. NMR 6 (1995) 277.

53. D. S. Garrett, R. Powers, A. M. Gronenborn, and G. M. Clore, J. Magn. Reson. 95 (1991) 214.

54. C. Bartels, T. Xia, M. Billeter, P. Güntert, and K. Wüthrich, J. Biomol. NMR 6 (1995) 1.

55. B. A. Johnson, Methods Mol. Biol. 278 (2004) 313.

56. R. L. J. Keller, The Computer Aided Resonance Assignment Tutorial. CANTINA Verlag, Goldau (2004).

57. D. Malmodin, C. H. Papavoine, and M. Billeter, J. Biomol. NMR 27 (2003) 69.

58. B. E. Coggins and P. Zhou, J. Biomol. NMR 26 (2003) 93.

59. S. G. Hyberts and G. Wagner, J. Biomol. NMR 26 (2003) 335.

60. J. E. Masse and R. Keller, J. Magn. Reson. 174 (2005) 133.

61. J. Wang, T. Wang, E. R. Zuiderweg, and G. M. Crippen, J. Biomol. NMR 33 (2005) 261.

62. D. S. Wishart, B. D. Sykes, and F. M. Richards, J. Mol. Biol. 222 (1991) 311.

63. T. Stangler, L. M. Mayr, A. J. Dingley, C. Luge, and D. Willbold, J. Biomol. NMR 21 (2001) 183.

64. V. F. Bystrov, Prog. NMR Spectrosc. 10 (1976) 41.

65. A. C. Wang and A. Bax, J. Am. Chem. Soc. 118 (1996) 2483.

66. C. Griesinger, O. W. Sorensen, and R. R. Ernst, J. Chem. Phys. 85 (1986) 6837.

67. A. Bax, G. W. Vuister, S. Grzesiek, F. Delaglio, A. C. Wang, R. Tschudin, and G. Zhu, Methods Enzymol. 239 (1994) 79.

68. B. Reif, M. Hennig, and C. Griesinger, Science 276 (1997) 1230. 
69. D. Yang, R. Konrat, and L. E. Kay, J. Am. Chem. Soc. 119 (1997) 11938.

70. G. Cornilescu, F. Delaglio, and A. Bax, J. Biomol. NMR 13 (1999) 289.

71. M. P. Williamson and T. Asakura, J. Magn. Reson. B 101 (1993) 63.

72. J. Kuszewski, A. M. Gronenborn, and G. M. Clore, J. Magn. Reson. B 107 (1995) 293.

73. A. J. Dingley and S. Grzesiek, J. Am. Chem. Soc. 120 (1998) 8293.

74. K. Pervushin, A. Ono, C. Fernandez, T. Szyperski, M. Kainosho, and K. Wuthrich, Proc. Natl. Acad. Sci. USA 95 (1998) 14147.

75. S. Grzesiek, F. Cordier, and A. J. Dingley, Methods Enzymol. 338 (2001) 111.

76. J. R. Tolman, J. M. Flanagan, M. A. Kennedy, and J. H. Prestegard, Proc. Natl. Acad. Sci. USA 92 (1995) 9279.

77. N. Tjandra, D. S. Garrett, A. M. Gronenborn, A. Bax, and G. M. Clore, Nat. Struct. Biol. 4 (1997) 443.

78. G. Cornilescu and A. Bax, J. Am. Chem. Soc. 122 (2000) 10143.

79. W. Y. Choy, M. Tollinger, G. A. Mueller, and L. E. Kay, J. Biomol. NMR 21 (2001) 31.

80. J. L. Battiste and G. Wagner, Biochemistry 39 (2000) 5355.

81. V. Gaponenko, J. W. Howarth, L. Columbus, G. Gasmi-Seabrook, J. Yuan, W. L. Hubbell, and P. R. Rosevear, Protein Sci. 9 (2000) 302.

82. I. Bertini, C. Luchinat, G. Parigi, and R. Pierattelli, ChemBioChem 6 (2005) 1536.

83. G. M. Clore and A. M. Gronenborn, Crit Rev. Biochem. Mol. Biol. 24 (1989) 479.

84. P. Guntert, C. Mumenthaler, and K. Wuthrich, J. Mol. Biol. 273 (1997) 283.

85. A. T. Brunger, P. D. Adams, G. M. Clore, W. L. DeLano, P. Gros, R. W. GrosseKunstleve, J. S. Jiang, J. Kuszewski, M. Nilges, N. S. Pannu, R. J. Read, L. M. Rice, T. Simonson, and G. L. Warren, Acta Crystallogr. D. Biol. Crystallogr. 54 (1998) 905.

86. C. D. Schwieters, J. J. Kuszewski, N. Tjandra, and G. M. Clore, J. Magn. Reson. 160 (2003) 65.

87. M. Nilges, G. M. Clore, and A. M. Gronenborn, FEBS Lett. 229 (1988) 317.

88. E. G. Stein, L. M. Rice, and A. T. Brunger, J. Magn. Reson. 124 (1997) 154.

89. J. Kuszewski, A. M. Gronenborn, and G. M. Clore, Protein Sci. 5 (1996) 1067.

90. J. Kuszewski and G. M. Clore, J. Magn. Reson. 146 (2000) 249.

91. T. Stangler, L. M. Mayr, and D. Willbold, J. Biol. Chem. 277 (2002) 13363.

92. H. Wang, F. K. Bedford, N. J. Brandon, S. J. Moss, and R. W. Olsen, Nature 397 (1999) 69.

93. S. J. Moss and T. G. Smart, Nat. Rev. Neurosci. 2 (2001) 240.

94. I. Tanida, M. Komatsu, T. Ueno, and E. Kominami, Biochem. Biophys. Res. Commun. 300 (2003) 637.

95. P. Guntert, W. Braun, M. Billeter, and K. Wüthrich, J. Am. Chem. Soc. 111 (1989) 3997.

96. A. L. Morris, M. W. MacArthur, E. G. Hutchinson, and J. M. Thornton, Proteins 12 (1992) 345.

97. R. A. Laskowski, J. A. Rullmannn, M. W. MacArthur, R. Kaptein, and J. M. Thornton, J. Biomol. NMR 8 (1996) 477.

98. M. Habeck, W. Rieping, J. P. Linge, and M. Nilges, Methods Mol. Biol. 278 (2004) 379.

99. P. Guntert, Methods Mol. Biol. 278 (2004) 353.

100. P. Güntert, Prog. NMR Spectrosc. 43 (2003) 105.

101. L. E. Kay, Nat. Struct. Biol. 5 (NMR Suppl.) (1998) 513.

102. R. Ishima and D. A. Torchia, Nat. Struct. Biol. 7 (2000) 740.

103. R. Bruschweiler, Curr. Opin. Struct. Biol. 13 (2003) 175.

104. J. G. Kempf and J. P. Loria, Cell Biochem. Biophys. 37 (2002) 187. 
105. A. G. Palmer, III, Chem. Rev. 104 (2004) 3623.

106. A. G. Palmer, III, Annu. Rev. Biophys. Biomol. Struct. 30 (2001) 129.

107. J. W. Peng and G. Wagner, J. Magn. Reson. 98 (1992) 308.

108. N. A. Farrow, O. Zhang, A. Szabo, D. A. Torchia, and L. E. Kay, J. Biomol. NMR 6 (1995) 153.

109. R. J. Wittebort and A. Szabo, J. Chem. Phys. 69 (1978) 1722.

110. G. Lipari and A. Szabo, J. Am. Chem. Soc. 104 (1982) 4546.

111. G. M. Clore, A. Szabo, A. Bax, L. E. Kay, P. C. Driscoll, and A. M. Gronenborn, J. Am. Chem. Soc. 112 (1990) 4989.

112. K. H. Mayo, V. A. Daragan, D. Idiyatullin, and I. Nesmelova, J. Magn. Reson. 146 (2000) 188.

113. S. F. Lienin, T. Bremi, B. Brutscher, R. Bruschweiler, and R. R. Ernst, J. Am. Chem. Soc. 120 (1998) 9870.

114. A. G. Palmer, III, C. D. Kroenke, and J. P. Loria, Methods Enzymol. 339 (2001) 204.

115. M. Akke, Curr. Opin. Struct. Biol. 12 (2002) 642.

116. R. A. Atkinson and B. Kieffer, Prog. NMR Spectrosc. 44 (2004) 141.

117. A. G. Palmer, III, M. J. Grey, and C. Wang, Methods Enzymol. 394 (2005) 430.

118. M. Blackledge, Prog. NMR Spectrosc. 46 (2005) 23.

119. J. R. Tolman, H. M. al Hashimi, L. E. Kay, and J. H. Prestegard, J. Am. Chem. Soc. 123 (2001) 1416.

120. J. Meiler, J. J. Prompers, W. Peti, C. Griesinger, and R. Bruschweiler, J. Am. Chem. Soc. 123 (2001) 6098.

121. J. R. Tolman, J. Am. Chem. Soc. 124 (2002) 12020.

122. P. Bernado and M. Blackledge, J. Am. Chem. Soc. 126 (2004) 4907.

123. G. Bouvignies, P. Bernado, and M. Blackledge, J. Magn. Reson. 173 (2005) 328.

124. G. Hernandez, F. E. Jenney, Jr., M. W. Adams, and D. M. LeMaster, Proc. Natl. Acad. Sci. USA 97 (2000) 3166.

125. P. Schanda and B. Brutscher, J. Am. Chem. Soc. 127 (2005) 8014.

126. M. M. Krishna, L. Hoang, Y. Lin, and S. W. Englander, Methods 34 (2004) 51.

127. P. Styles, N. F. Soffe, C. A. Scott, D. A. Cragg, F. Row, D. J. White, and P. C. J. White, J. Magn. Reson. 60 (1984) 397.

128. P. J. Hajduk, T. Gerfin, J. M. Boehlen, M. Haberli, D. Marek, and S. W. Fesik, J. Med. Chem. 42 (1999) 2315.

129. A. Bax and S. S. Pochapsky, J. Magn. Reson. 99 (1992) 638.

130. M. Piotto, V. Saudek, and V. Sklenar, J. Biomol. NMR 2 (1992) 661.

131. A. Dehner and H. Kessler, ChemBioChem 6 (2005) 1550.

132. R. Freeman and E. Kupce, J. Biomol. NMR 27 (2003) 101.

133. H. S. Atreya and T. Szyperski, Methods Enzymol. 394 (2005) 78.

134. S. Kim and T. Szyperski, J. Am. Chem. Soc. 125 (2003) 1385.

135. E. Kupce and R. Freeman, J. Biomol. NMR 25 (2003) 349.

136. E. Kupce and R. Freeman, J. Am. Chem. Soc. 126 (2004) 6429.

137. S. Hiller, F. Fiorito, K. Wuthrich, and G. Wider, Proc. Natl. Acad. Sci. USA 102 (2005) 10876.

138. L. Frydman, T. Scherf, and A. Lupulescu, Proc. Natl. Acad. Sci. USA 99 (2002) 15858.

139. L. Frydman, A. Lupulescu, and T. Scherf, J. Am. Chem. Soc. 125 (2003) 9204.

140. Y. Shrot and L. Frydman, J. Am. Chem. Soc. 125 (2003) 11385.

141. R. A. Venters, B. T. Farmer, C. A. Fierke, and L. D. Spicer, J. Mol. Biol. 264 (1996) 1101.

142. L. E. Kay and K. H. Gardner, Curr. Opin. Struct. Biol. 7 (1997) 722.

143. S. Grzesiek, J. Anglister, H. Ren, and A. Bax, J. Am. Chem. Soc. 115 (1993) 4369 . 
144. M. A. Markus, K. T. Dayie, P. Matsudaira, and G. Wagner, J. Magn. Reson. B 105 (1994) 192.

145. T. Yamazaki, W. Lee, C. H. Arrowsmith, D. R. Muhandiram, and L. E. Kay, J. Am. Chem. Soc. 116 (1994) 11655.

146. X. Shan, K. H. Gardner, D. R. Muhandiram, L. E. Kay, and C. H. Arrowsmith, J. Biomol. NMR 11 (1998) 307.

147. K. H. Gardner, X. Zhang, K. Gehring, and L. E. Kay, J. Am. Chem. Soc. 120 (1998) 11738 .

148. D. S. Garrett, Y. J. Seok, A. Peterkofsky, A. M. Gronenborn, and G. M. Clore, Nat. Struct. Biol. 6 (1999) 166.

149. G. Wider and K. Wuthrich, Curr. Opin. Struct. Biol. 9 (1999) 594.

150. K. Pervushin, in Protein NMR for the Millenium, N. Rama Krishna and L. J. Berliner (Eds.). Kluwer Academic/Plenum Publishers, New York (2003), p. 3.

151. R. L. Vold and R. R. Vold, Prog. NMR Spectrosc. 12 (1978) 79.

152. M. Gueron, J. L. Leroy, and R. H. Griffey, J. Am. Chem. Soc. 105 (1983) 7262.

153. M. Goldman, J. Magn. Reson. 60 (1984) 437.

154. K. V. Pervushin, G. Wider, R. Riek, and K. Wuthrich, Proc. Natl. Acad. Sci. USA 96 (1999) 9607.

155. K. Pervushin, G. Wider, and K. Wüthrich, J. Biomol. NMR 12 (1998) 345.

156. D. Yang and L. E. Kay, J. Biomol. NMR 13 (1999) 3.

157. K. Pervushin, R. Riek, G. Wider, and K. Wüthrich, J. Am. Chem. Soc. 120 (1998) 6394.

158. A. Meissner and O. W. Sorensen, J. Magn. Reson. 139 (1999) 447.

159. R. Riek, K. Pervushin, C. Fernandez, M. Kainosho, and K. Wuthrich, J. Am. Chem. Soc. 123 (2001) 658.

160. P. K. Madhu, R. Grandori, K. Hohenthanner, P. K. Mandal, and N. Muller, J. Biomol. NMR 20 (2001) 31.

161. V. Tugarinov, P. M. Hwang, J. E. Ollerenshaw, and L. E. Kay, J. Am. Chem. Soc. 125 (2003) 10420.

162. K. Wuthrich, Nat. Struct. Biol. 5 (NMR Suppl.) (1998) 492.

163. R. Gerald, T. Bernhard, U. Haeberlen, J. Rendell, and S. Opella, J. Am. Chem. Soc. 115 (1993) 777.

164. C. H. Wu, A. Ramamoorthy, L. M. Gierasch, and S. J. Opella, J. Am. Chem. Soc. 117 (1995) 6148.

165. M. Salzmann, G. Wider, K. Pervushin, and K. Wuthrich, J. Biomol. NMR 15 (1999) 181.

166. J. Weigelt, J. Am. Chem. Soc. 120 (1998) 10778.

167. G. A. Morris and R. Freeman, J. Am. Chem. Soc. 101 (1979) 760.

168. C. Dalvit, J. Magn. Reson. 97 (1992) 645.

169. R. Brüschweiler and R. R. Ernst, J. Chem. Phys. 96 (1992) 1758.

170. R. Riek, G. Wider, K. Pervushin, and K. Wuthrich, Proc. Natl. Acad. Sci. USA 96 (1999) 4918.

171. A. P. Hansen, A. M. Petros, A. P. Mazar, T. M. Pederson, A. Rueter, and S. W. Fesik, Biochemistry 31 (1992) 12713.

172. W. J. Metzler, M. Wittekind, V. Goldfarb, L. Mueller, and B. T. Farmer, J. Am. Chem. Soc. 118 (1996) 6800.

173. M. K. Rosen, K. H. Gardner, R. C. Willis, W. E. Parris, T. Pawson, and L. E. Kay, J. Mol. Biol. 263 (1996) 627.

174. V. Tugarinov and L. E. Kay, J. Biomol. NMR 28 (2004) 165.

175. G. Zhu, Y. Xia, D. Lin, and X. Gao, Methods Mol. Biol. 278 (2004) 57.

176. M. Salzmann, K. Pervushin, G. Wider, H. Senn, and K. Wuthrich, Proc. Natl. Acad. Sci. USA 95 (1998) 13585.

177. R. Konrat, D. Yang, and L. E. Kay, J. Biomol. NMR 15 (1999) 309. 
178. D. Yang and L. E. Kay, J. Am. Chem. Soc. 121 (1999) 2571.

179. F. Lohr, S. Pfeiffer, Y. J. Lin, J. Hartleib, O. Klimmek, and H. Ruterjans, J. Biomol. NMR 18 (2000) 337.

180. B. Brutscher, J. Boisbouvier, A. Pardi, D. Marion, and J. P. Simorre, J. Am. Chem. Soc. 120 (1998) 11845.

181. G. Zhu, X. M. Kong, and K. H. Sze, J. Biomol. NMR 13 (1999) 77.

182. A. Meissner and O. W. Sorensen, J. Magn. Reson. 140 (1999) 499.

183. A. Meissner and O. W. Sorensen, J. Magn. Reson. 142 (2000) 195.

184. V. Tugarinov, L. E. Kay, I. Ibraghimov, and V. Y. Orekhov, J. Am. Chem. Soc. 127 (2005) 2767.

185. D. Yang, R. A. Venters, G. A. Mueller, W. Y. Choy, and L. E. Kay, J. Biomol. NMR 14 (1999) 333.

186. G. Kontaxis, G. M. Clore, and A. Bax, J. Magn. Reson. 143 (2000) 184.

187. P. Permi and A. Annila, J. Biomol. NMR 16 (2000) 221.

188. S. W. Fesik and E. R. Zuiderweg, Q. Rev. Biophys. 23 (1990) 97.

189. G. M. Clore and A. M. Gronenborn, Prog. NMR Spectrosc. 23 (1991) 43.

190. D. Cowburn and T. W. Muir, Methods Enzymol. 339 (2001) 41.

191. T. W. Muir, D. Sondhi, and P. A. Cole, Proc. Natl. Acad. Sci. USA 95 (1998) 6705.

192. T. Yamazaki, T. Otomo, N. Oda, Y. Kyogoku, K. Uegaki, N. Ito, Y. Ishino, and H. Nakamura, J. Am. Chem. Soc. 120 (1998) 5591.

193. C. Fernandez and G. Wider, Curr. Opin. Struct. Biol. 13 (2003) 570.

194. G. Wider, Methods Enzymol. 394 (2005) 382.

195. C. Fernandez, K. Adeishvili, and K. Wuthrich, Proc. Natl. Acad. Sci. USA 98 (2001) 2358.

196. A. Arora, F. Abildgaard, J. H. Bushweller, and L. K. Tamm, Nat. Struct. Biol. 8 (2001) 334.

197. P. M. Hwang, W. Y. Choy, E. I. Lo, L. Chen, J. D. Forman-Kay, C. R. Raetz, G. G. Prive, R. E. Bishop, and L. E. Kay, Proc. Natl. Acad. Sci. USA 99 (2002) 13560.

198. K. Oxenoid, H. J. Kim, J. Jacob, F. D. Sonnichsen, and C. R. Sanders, J. Am. Chem. Soc. 126 (2004) 5048.

199. J. Fiaux, E. B. Bertelsen, A. L. Horwich, and K. Wuthrich, Nature 418 (2002) 207.

200. R. Horst, E. B. Bertelsen, J. Fiaux, G. Wider, A. L. Horwich, and K. Wuthrich, Proc. Natl. Acad. Sci. USA 102 (2005) 12748.

201. D. J. Hamel and F. W. Dahlquist, J. Am. Chem. Soc. 127 (2005) 9676.

202. V. Tugarinov, W. Y. Choy, V. Y. Orekhov, and L. E. Kay, Proc. Natl. Acad. Sci. USA 102 (2005) 622.

203. J. P. Loria, M. Rance, and A. G. Palmer, III, J. Biomol. NMR 15 (1999) 151.

204. J. G. Kempf, J. Y. Jung, N. S. Sampson, and J. P. Loria, J. Am. Chem. Soc. 125 (2003) 12064.

205. D. M. Korzhnev, K. Kloiber, V. Kanelis, V. Tugarinov, and L. E. Kay, J. Am. Chem. Soc. 126 (2004) 3964.

206. V. Tugarinov, J. E. Ollerenshaw, and L. E. Kay, J. Am. Chem. Soc. 127 (2005) 8214.

207. V. Tugarinov and L. E. Kay, ChemBioChem 6 (2005) 1567.

208. A. Eletsky, H. S. Atreya, G. Liu, and T. Szyperski, J. Am. Chem. Soc. 127 (2005) 14578.

209. G. Zhu, Y. Xia, D. Lin, and X. Gao, Methods Mol. Biol. 278 (2004) 161.

210. V. Tugarinov and L. E. Kay, Biochemistry 44 (2005) 15970.

211. R. Sprangers, A. Gribun, P. M. Hwang, W. A. Houry, and L. E. Kay, Proc. Natl. Acad. Sci. USA 102 (2005) 16678. 
212. L. K. Tamm, F. Abildgaard, A. Arora, H. Blad, and J. H. Bushweller, FEBS Lett. 555 (2003) 139.

213. C. Fernandez, C. Hilty, G. Wider, P. Guntert, and K. Wuthrich, J. Mol. Biol. 336 (2004) 1211.

214. P. M. Hwang and L. E. Kay, Methods Enzymol. 394 (2005) 335.

215. A. Bax, Protein Sci. 12 (2003) 1.

216. J. H. Prestegard, K. L. Mayer, H. Valafar, and G. C. Benison, Methods Enzymol. 394 (2005) 175.

217. A. Bax and N. Tjandra, J. Biomol. NMR 10 (1997) 289.

218. M. R. Hansen, L. Mueller, and A. Pardi, Nat. Struct. Biol. 5 (1998) 1065.

219. B. E. Ramirez and A. Bax, J. Am. Chem. Soc. 120 (1998) 9106.

220. J. H. Prestegard, C. M. Bougault, and A. I. Kishore, Chem. Rev. 104 (2004) 3519.

221. R. Tycko, F. J. Blanco, and Y. Ishii, J. Am. Chem. Soc. 122 (2000) 9340.

222. H. J. Sass, G. Musco, S. J. Stahl, P. T. Wingfield, and S. Grzesiek, J. Biomol. NMR 18 (2000) 303.

223. C. Ma and S. J. Opella, J. Magn. Reson. 146 (2000) 381.

224. J. Feeny, B. Birdsall, A. F. Bradbury, R. R. Biekofsky, and P. M. Bayley, J. Biomol. NMR 21 (2001) 41.

225. J. Wohnert, K. J. Franz, M. Nitz, B. Imperiali, and H. Schwalbe, J. Am. Chem. Soc. 125 (2003) 13338.

226. A. Meissner, J. O. Duus, and O. W. Sorensen, J. Biomol. NMR 10 (1997) 89.

227. M. Ottiger, F. Delaglio, and A. Bax, J. Magn. Reson. 131 (1998) 373.

228. P. Andersson, A. Annila, and G. Otting, J. Magn. Reson. 133 (1998) 364.

229. F. Cordier, A. J. Dingley, and S. Grzesiek, J. Biomol. NMR 13 (1999) 175.

230. K. Ding and A. M. Gronenborn, J. Magn. Reson. 163 (2003) 208.

231. D. Yang, J. R. Tolman, N. K. Goto, and L. E. Kay, J. Biomol. NMR 12 (1998) 325.

232. M. Ottiger, F. Delaglio, J. L. Marquardt, N. Tjandra, and A. Bax, J. Magn. Reson. 134 (1998) 365.

233. R. L. McFeeters, C. A. Fowler, V. V. Gaponenko, and R. A. Byrd, J. Biomol. NMR $31(2005) 35$.

234. Y. X. Wang, J. L. Marquardt, P. Wingfield, S. J. Stahl, S. Lee-Huang, D. Torchia, and A. Bax, J. Am. Chem. Soc. 120 (1998) 7385.

235. V. Tugarinov and L. E. Kay, J. Mol. Biol. 327 (2003) 1121.

236. G. M. Clore, A. M. Gronenborn, and A. Bax, J. Magn. Reson. 133 (1998) 216.

237. N. Tjandra, J. G. Omichinski, A. M. Gronenborn, G. M. Clore, and A. Bax, Nat. Struct. Biol. 4 (1997) 732.

238. C. A. Bewley and G. M. Clore, J. Am. Chem. Soc. 122 (2000) 6009.

239. M. Revington, Y. Zhang, G. N. Yip, A. V. Kurochkin, and E. R. Zuiderweg, J. Mol. Biol. 349 (2005) 163.

240. N. U. Jain, T. J. Wyckoff, C. R. Raetz, and J. H. Prestegard, J. Mol. Biol. 343 (2004) 1379.

241. M. W. Fischer, J. A. Losonczi, J. L. Weaver, and J. H. Prestegard, Biochemistry 38 (1999) 9013.

242. D. T. Braddock, M. Cai, J. L. Baber, Y. Huang, and G. M. Clore, J. Am. Chem. Soc. 123 (2001) 8634.

243. J. C. Hus, D. Marion, and M. Blackledge, J. Am. Chem. Soc. 123 (2001) 1541.

244. F. Tian, H. Valafar, and J. H. Prestegard, J. Am. Chem. Soc. 123 (2001) 11791.

245. A. W. Giesen, S. W. Homans, and J. M. Brown, J. Biomol. NMR 25 (2003) 63.

246. H. Valafar, K. L. Mayer, C. M. Bougault, P. D. LeBlond, F. E. Jenney, Jr., P. S. Brereton, M. W. Adams, and J. H. Prestegard, J. Struct. Funct. Genomics 5 (2004) 241.

247. A. Annila, H. Aitio, E. Thulin, and T. Drakenberg, J. Biomol. NMR 14 (1999) 223.

248. F. Delaglio, G. Kontaxis, and A. Bax, J. Am. Chem. Soc. 122 (2000) 2142. 
249. M. Andrec, P. Du, and R. M. Levy, J. Am. Chem. Soc. 123 (2001) 1222.

250. G. Kontaxis, F. Delaglio, and A. Bax, Methods Enzymol. 394 (2005) 42.

251. K. Takeuchi and G. Wagner, Curr. Opin. Struct. Biol. 16 (2006) 109.

252. G. Otting, Curr. Opin. Struct. Biol. 3 (1993) 760.

253. A. L. Breeze, Prog. NMR Spectrosc. 36 (2000) 323.

254. M. Ikura and A. Bax, J. Am. Chem. Soc. 114 (1992) 2433.

255. K. J. Walters, H. Matsuo, and G. Wagner, J. Am. Chem. Soc. 119 (1997) 5958.

256. G. Otting, H. Senn, G. Wagner, and K. Wuthrich, J. Magn. Reson. 70 (1986) 500.

257. H. Kogler, O. W. Sorensen, G. Bodenhausen, and R.R. Ernst, J. Magn. Reson. 55 (1983) 157.

258. C. Zwahlen, P. Legault, S. J. F. Vincent, J. Greenblatt, R. Konrat, and L. E. Kay, J. Am. Chem. Soc. 119 (1997) 6711.

259. H. Takahashi, T. Nakanishi, K. Kami, Y. Arata, and I. Shimada, Nat. Struct. Biol. 7 (2000) 220.

260. I. Shimada, Methods Enzymol. 394 (2005) 483.

261. Y. Paterson, S. W. Englander, and H. Roder, Science 249 (1990) 755.

262. M. Gorlach, M. Wittekind, R. A. Beckman, L. Mueller, and G. Dreyfuss, EMBO J. 11 (1992) 3289.

263. Y. Chen, J. Reizer, M. H. Saier, Jr., W. J. Fairbrother, and P. E. Wright, Biochemistry 32 (1993) 32.

264. M. L. Reese and V. Dotsch, J. Am. Chem. Soc. 125 (2003) 14250.

265. H. Matsuo, K. J. Walters, K. Teruya, T. Tanaka, G. T. Gassner, S. J. Lippard, Y. Kyogoku, and G. Wagner, J. Am. Chem. Soc. 121 (1999) 9903.

266. J. Zamoon, F. Nitu, C. Karim, D. D. Thomas, and G. Veglia, Proc. Natl. Acad. Sci. USA 102 (2005) 4747.

267. J. Vaynberg, T. Fukuda, K. Chen, O. Vinogradova, A. Velyvis, Y. Tu, L. Ng, C. Wu, and J. Qin, Mol. Cell. 17 (2005) 513.

268. J. Vaynberg and J. Qin, Trends Biotechnol. 24 (2006) 22.

269. P. Balaram, A. A. Bothner-By, and E. Breslow, Biochemistry 12 (1973) 4695.

270. J. P. Albrand, B. Birdsall, J. Feeney, G. C. K. Roberts, and A. S. V. Burgen, Int. J. Biolog. Macromol. 1 (1979) 37.

271. C. B. Post, Curr. Opin. Struct. Biol. 13 (2003) 581.

272. T. Scherf and J. Anglister, Biophys. J. 64 (1993) 754.

273. T. Carlomagno, Annu. Rev. Biophys. Biomol. Struct. 34 (2005) 245.

274. T. Carlomagno, I. C. Felli, M. Czech, R. Fischer, M. Sprinzl, and C. Griesinger, J. Am. Chem. Soc. 121 (1999) 1945.

275. M. J. J. Blommers, W. Stark, C. E. Jones, D. Head, C. E. Owen, and W. Jahnke, J. Am. Chem. Soc. 121 (1999) 1949.

276. T. Carlomagno, V. M. Sanchez, M. J. Blommers, and C. Griesinger, Angew. Chem. Int. Ed. Engl. 42 (2003) 2515.

277. B. W. Koenig, D. C. Mitchell, S. König, S. Grzesiek, B. J. Litman, and A. Bax, J. Biomol. NMR 16 (2000) 121.

278. B. W. Koenig, ChemBioChem 3 (2002) 975.

279. B. W. Koenig, G. Kontaxis, D. C. Mitchell, J. M. Louis, B. J. Litman, and A. Bax, J. Mol. Biol. 322 (2002) 441.

280. D. G. Lambright, J. Sondek, A. Bohm, N. P. Skiba, H. E. Hamm, and P. B. Sigler, Nature 379 (1996) 311.

281. K. Palczewski, T. Kumasaka, T. Hori, C. A. Behnke, H. Motoshima, B. A. Fox, T. Le, I, D. C. Teller, T. Okada, R. E. Stenkamp, M. Yamamoto, and M. Miyano, Science 289 (2000) 739.

282. K. Cai, Y. Itoh, and H. G. Khorana, Proc. Natl. Acad. Sci. USA 98 (2001) 4877.

283. T. Nakanishi, M. Miyazawa, M. Sakakura, H. Terasawa, H. Takahashi, and I. Shimada, J. Mol. Biol. 318 (2002) 245. 
284. K. Takeuchi, M. Yokogawa, T. Matsuda, M. Sugai, S. Kawano, T. Kohno, H. Nakamura, H. Takahashi, and I. Shimada, Structure 11 (2003) 1381.

285. K. Takeuchi, H. Takahashi, M. Sugai, H. Iwai, T. Kohno, K. Sekimizu, S. Natori, and I. Shimada, J. Biol. Chem. 279 (2004) 4981.

286. A. D. van Dijk, D. Fushman, and A. M. Bonvin, Proteins 60 (2005) 367.

287. A. M. Bonvin, R. Boelens, and R. Kaptein, Curr. Opin. Chem. Biol. 9 (2005) 501.

288. G. M. Clore, Proc. Natl. Acad. Sci. USA 97 (2000) 9021.

289. X. P. Xu and D. A. Case, J. Biomol. NMR 21 (2001) 321.

290. M. A. McCoy and D. F. Wyss, J. Am. Chem. Soc. 124 (2002) 2104.

291. A. Fahmy and G. Wagner, J. Am. Chem. Soc. 124 (2002) 1241.

292. C. Dominguez, R. Boelens, and A. M. Bonvin, J. Am. Chem. Soc. 125 (2003) 1731.

293. G. M. Clore and C. D. Schwieters, J. Am. Chem. Soc. 125 (2003) 2902.

294. X. J. Morelli, P. N. Palma, F. Guerlesquin, and A. C. Rigby, Protein Sci. 10 (2001) 2131.

295. A. Dobrodumov and A. M. Gronenborn, Proteins 53 (2003) 18.

296. E. R. Zuiderweg, Biochemistry 41 (2002) 1.

297. M. Pellecchia, D. L. Montgomery, S. Y. Stevens, C. W. van der Kooi, H. P. Feng, L. M. Gierasch, and E. R. Zuiderweg, Nat. Struct. Biol. 7 (2000) 298.

298. S. Y. Stevens, S. Sanker, C. Kent, and E. R. Zuiderweg, Nat. Struct. Biol. 8 (2001) 947.

299. M. A. McCoy and D. F. Wyss, J. Am. Chem. Soc. 124 (2002) 11758.

300. C. P. Jaroniec, J. D. Kaufman, S. J. Stahl, M. Viard, R. Blumenthal, P. T. Wingfield, and A. Bax, Biochemistry 44 (2005) 16167.

301. G. A. Mueller, A. M. Smith, M. D. Chapman, G. S. Rule, and D. C. Benjamin, J. Biol. Chem. 276 (2001) 9359.

302. D. C. Williams, Jr., D. C. Benjamin, R. J. Poljak, and G. S. Rule, J. Mol. Biol. 257 (1996) 866.

303. J. R. Engen, W. H. Gmeiner, T. E. Smithgall, and D. L. Smith, Biochemistry 38 (1999) 8926.

304. M. Sakakura, S. Noba, P. A. Luchette, I. Shimada, and R. S. Prosser, J. Am. Chem. Soc. 127 (2005) 5826.

305. S. Arumugam, C. L. Hemme, N. Yoshida, K. Suzuki, H. Nagase, M. Berjanskii, B. Wu, and S. R. Van Doren, Biochemistry 37 (1998) 9650.

306. D. K. Chang, S. F. Cheng, and W. J. Chien, J. Virol. 71 (1997) 6593.

307. T. Scherf, R. Hiller, and J. Anglister, FASEB J. 9 (1995) 120.

308. H. Wang, A. V. Kurochkin, Y. Pang, W. Hu, G. C. Flynn, and E. R. Zuiderweg, Biochemistry 37 (1998) 7929.

309. M. Ubbink, M. Ejdeback, B. G. Karlsson, and D. S. Bendall, Structure 6 (1998) 323.

310. M. Pellecchia, D. S. Sem, and K. Wuthrich, Nat. Rev. Drug Discov. 1 (2002) 211.

311. B. J. Stockman and C. Dalvit, Prog. NMR Spectrosc. 41 (2002) 187.

312. C. A. Lepre, J. M. Moore, and J. W. Peng, Chem. Rev. 104 (2004) 3641.

313. S. B. Shuker, P. J. Hajduk, R. P. Meadows, and S. W. Fesik, Science 274 (1996) 1531.

314. B. Meyer and T. Peters, Angew. Chem. Int. Ed. Engl. 42 (2003) 864.

315. W. Jahnke, A. Florsheimer, M. J. Blommers, C. G. Paris, J. Heim, C. M. Nalin, and L. B. Perez, Curr. Top. Med. Chem. 3 (2003) 69.

316. C. Dalvit, M. Flocco, S. Knapp, M. Mostardini, R. Perego, B. J. Stockman, M. Veronesi, and M. Varasi, J. Am. Chem. Soc. 124 (2002) 7702.

317. P. J. Hajduk, E. T. Olejniczak, and S. W. Fesik, J. Am. Chem. Soc. 119 (1997) 12257. 
318. W. Jahnke, L. B. Perez, C. G. Paris, A. Strauss, G. Fendrich, and C. M. Nalin, J. Am. Chem. Soc. 122 (2000) 7394.

319. W. Jahnke, S. Rudisser, and M. Zurini, J. Am. Chem. Soc. 123 (2001) 3149.

320. B. Meyer, T. Weimar, and T. Peters, Eur. J. Biochem. 246 (1997) 705.

321. M. Mayer and B. Meyer, Angew. Chem. Int. Ed. Engl. 38 (1999) 1784.

322. R. Meinecke and B. Meyer, J. Med. Chem. 44 (2001) 3059.

323. A. J. Benie, R. Moser, E. Bauml, D. Blaas, and T. Peters, J. Am. Chem. Soc. 125 (2003) 14.

324. B. Claasen, M. Axmann, R. Meinecke, and B. Meyer, J. Am. Chem. Soc. 127 (2005) 916.

325. F. Markwardt, H. Landmann, and P. Walsmann, Eur. J. Biochem. 6 (1968) 502.

326. M. Mayer and B. Meyer, J. Am. Chem. Soc. 123 (2001) 6108.

327. L. Herfurth, B. Ernst, B. Wagner, D. Ricklin, D. S. Strasser, J. L. Magnani, A. J. Benie, and T. Peters, J. Med. Chem. 48 (2005) 6879.

328. J. Yan, A. D. Kline, H. Mo, M. J. Shapiro, and E. R. Zartler, J. Magn. Reson. 163 (2003) 270.

329. V. Jayalakshmi and N. R. Krishna, J. Magn. Reson. 155 (2002) 106.

330. C. Dalvit, P. Pevarello, M. Tato, M. Veronesi, A. Vulpetti, and M. Sundstrom, J. Biomol. NMR 18 (2000) 65.

331. C. Dalvit, G. Fogliatto, A. Stewart, M. Veronesi, and B. Stockman, J. Biomol. NMR 21 (2001) 349.

332. D. Willbold, R. Rosin-Arbesfeld, H. Sticht, R. Frank, and P. Rosch, Science 264 (1994) 1584.

333. P. Rosch and D. Willbold, Science 272 (1996) 1672.

334. D. Willbold, A. U. Metzger, H. Sticht, K. C. Gallert, R. Voit, N. Dank, P. Bayer, G. Krauss, R. S. Goody, and P. Rosch, J. Mol. Biol. 277 (1998) 749.

335. D. Willbold, S. Hoffmann, and P. Rosch, Eur. J. Biochem. 245 (1997) 581.

336. K. Hänel, T. Stangler, M. Stoldt, and D. Willbold, J. Biomed. Sci. 13 (2006) in press. 